CRISTIANE SAVARIS

\title{
EFEITO dAS REABILITAÇÕES BUCAIS NA EFICIÊNCIA DE Ciclos MAstigatóRIOS - ANÁLISE EletromiográficA poR MEIO DA INTEGRAL DA ENVOLTÓRIA
}

Tese apresentada à Faculdade de Odontologia de Ribeirão Preto da Universidade de São Paulo, para obtenção do Título de Doutor em Odontologia.

Área de Concentração: Odontologia Restauradora, opção: Dentística.

Orientadora: Profa. Dra. Simone Cecilio Hallak Regalo. 
AUTORIZO A REPRODUÇÃO E/OU DIVULGAÇÃO TOTAL OU PARCIAL DA PRESENTE OBRA, POR QUALQUER MEIO CONVENCIONAL OU ELETRÖNICO, PARA FINS DE ESTUDO E PESQUISA, DESDE QUE CITADA A FONTE.

\section{FICHA CATALOGRÁFICA}

Preparada pela Biblioteca Central do Campus Administrativo de Ribeirão Preto / USP

Savaris, Cristiane

Efeito das reabilitações bucais na eficiência de ciclos mastigatórios - Análise eletromiográfica por meio da integral da envoltória. Ribeirão Preto, 2011.

82 p.: il. ; $30 \mathrm{~cm}$

Tese de Doutorado, apresentada à Faculdade de Odontologia de Ribeirão Preto - FORP/USP. Área de concentração: Odontologia Restauradora.

Orientadora: Regalo, Simone Cecilio Hallak.

1. Músculos mastigatórios 2. Mastigação. 3. Eficiência Mastigatória. 
Cristiane Savaris

Efeito das Reabilitações Bucais na Eficiência de Ciclos Mastigatórios - Análise Eletromiográfica por Meio da Integral da Envoltória.

Tese apresentada à Faculdade de Odontologia de Ribeirão Preto da Universidade de São Paulo para obtenção do título de Doutor em Odontologia Restauradora opção: Dentística.

Orientadora: Profa. Dra. Simone Cecilio Hallak Regalo.

Data da defesa:

\section{Banca Examinadora}

Prof. Dr.

Julgamento:

Assinatura:

Prof. Dr.

Julgamento:

Assinatura:

Prof. Dr.

Julgamento:

Assinatura:

Prof. Dr.

Julgamento:

Assinatura:

Prof. Dr.

Julgamento:

Assinatura: 


\section{QDedicatónia}

Aos meus pais Oaxis e Fuvelina

A minha história começa com vocês: verdadeiros presentes de Deus para mim! Exemplo maior de amor, coragem, perseverança, honestidade, trabalho, respeito, lealdade e união. É visível e nítido que o amor de Deus Pai transbordou em vocês e passou a inundar a todos nós seus filhos e pessoas ao redor. E mesmo que achasse as palavras, estas assim não traduziriam a minha emoção de tê-los em minha vida. Eu os amo muito!

\section{À minha amada tia Sadalena}

Quando existe amor, este é expresso de diferentes formas: pela cumplicidade, paciência, perdão, lágrimas, sorrisos, por um gesto ou até pelo ouvir e assim é conosco. É incrível, mas quando olho para mim, reconheço muito de você. Sou grata a Deus por ter o seu reflexo em mim. Mulher virtuosa, sábia, audaciosa, lutadora, líder nata! A minha vida tem sido engrandecida pelo seu amor, seu carinho e pelo seu estímulo. Mesmo depois de grandinha, encontro em minhas conquistas a sua constante presença!

\section{Aos meus irmãos Elisson, Oruma e Rabenta}

Meus "maninhos" que sempre estiveram comigo a todo o momento, a cada passo dado e escutaram as mais mirabolantes histórias da minha fase de deslumbramento. Acompanharam todo o meu amadurecimento pessoal e profissional. Obrigada pelo carinho, compreensão, apoio, exemplo e sem dúvida, pela amizade ilimitada que nos une!

À minha cunhada Aftiane, pelo apoio e incentivo. Você foi enxertada na figueira Savaris!

Aos meus sobrinhos Sophia e OPetra

Os mais novos membros da nossa família, que a cada dia enchem os nossos corações de alegria e amor! Vocês foram mais do que esperados. Renovo de Deus em nossa casa! 


\section{Agradecimentos Especiais}

\section{À QDeurs}

Agradeço ao Mestre dos Mestres, o principal e o mais importante personagem que me ajuda sempre, com muito amor, a escrever mais uma página da história da minha vida. Senhor eu te dou graças pelas pessoas maravilhosas que pusestes em meu caminho, sei que é através da presença delas que Tu ficas ao meu lado, sempre zelando por mim. Louvado seja porque Te revelas em gestos tão humanos que posso Te sentir sempre perto de mim.

À minha super orientadora, Oimone Gecilia Hallats Oregala

À você que me ajudou a concluir esta longa jornada que em alguns momentos pensei que nunca chegaria ao fim, no entanto, Deus permitiu que você entrasse na minha história e transformasse a minha vida acadêmica e o que era preto e branco se tornou colorido e alegre. Você caminhou comigo passo a passo neste fantástico mundo da Eletromiografia e mostrou-me um novo mundo de conhecimentos. Expresso aqui meu carinho, gratidão e profundo respeito a você, que tem sido exemplo de doação, dedicação, humildade, dignidade pessoal e principalmente pelo exemplo de profissional e pesquisadora que me norteará ao longo de toda a minha vida. Meu agradecimento será pouco, diante do muito que me foi oferecido. 


\section{Agradecimentos}

À Faculdade de Odontologia de Ribeirão Preto da Universidade de São Paulo, na pessoa do seu Diretor Prof. Dr. Osvaldo Luiz Bezzon.

Ao Departamento de Odontologia Restauradora, na pessoa do Prof. Dr. Jesus Djalma Pécora, cujo respeito e admiração crescem a cada dia, pela dedicação na busca por todos os interesses deste departamento.

À Coordenação do Curso de Pós-Graduação em Odontologia Restauradora da Faculdade de Odontologia de Ribeirão Preto da Universidade de São Paulo, na pessoa do Prof. Dr. Manoel Damião de Sousa Neto,

Ao Prof. Dr. Marcelo Oliveira Mazetto, vice-coordenador do curso de Pós-Graduação em Odontologia Restauradora da Faculdade de Odontologia de Ribeirão Preto da Universidade de São Paulo.

Aos Prof. Dr. César Bataglion e Profa. Dra. Selma Siéssere, pela participação como membros da banca examinadora em minha qualificação.

Aos demais Professores do Departamento de Odontologia Restauradora da Faculdade de Odontologia de Ribeirão Preto da Universidade de São Paulo.

Ao Prof. Dr. Jaime Eduardo Cecílio Hallak, pela atenção e contribuição na análise dos dados desse trabalho.

Ao secretário do Curso de Pós-Graduação em Odontologia Restauradora da Faculdade de Odontologia de Ribeirão Preto da Universidade de São Paulo, Carlos.

Aos técnicos e amigos Luiz Gustavo de Sousa e Paulo Batista de Vasconcelos, grandes profissionais e companheiros no Laboratório de Eletromiografia, sempre prontos a ajudar.

Aos técnicos do laboratório de Pesquisa em Dentística da Faculdade de Odontologia de Ribeirão Preto da Universidade de São Paulo, Patrícia Marchi e Reginaldo Santana. 
Às funcionárias da Seção de Pós-Graduação, Regiane Cristina Moi Sacilotto e Izabel Cristina Galino Sola, pela atenção enorme dispensada em todos os momentos.

Às funcionárias do Departamento de Odontologia Restauradora, Amália, Maria Isabel, Luisa e Rosângela, ótimas profissionais e sempre prestativas.

À CAPES, pelo financiamento da bolsa de doutorado.

Aos colegas de pós-graduação, Alessandra, Aline, Danielle, Vivian, Thaisa, Sandra, César, Daniel, e Walter, pelo respeito, amizade e intercâmbio de conhecimentos.

A todos os colegas do Laboratório de Eletromiografia, Flávia, Mariângela, Marcelo, Richard, companheiros nesse fascinante meio de pesquisa.

Às amigas Barbara Policarpo e Larissa de Azevedo pelo apoio, incentivo, companheirismo em todos os momentos. Grandes amigas que sempre tiveram palavras doces e divertidas tornando a caminhada mais alegre.

Aos voluntários dessa pesquisa, sem os quais nada disso teria sido possível.

A todos que, de alguma forma, colaboraram para que este trabalho fosse realizado, meu agradecimento muito especial. 
ÍNDICE

RESUMO

ABSTRACT

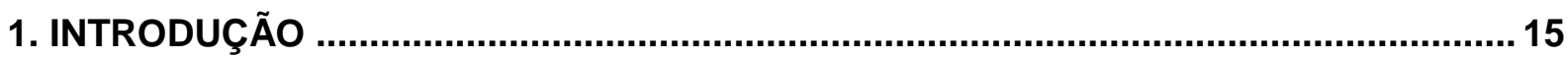

2. REVISÃO DA LITERATURA ............................................................................ 20

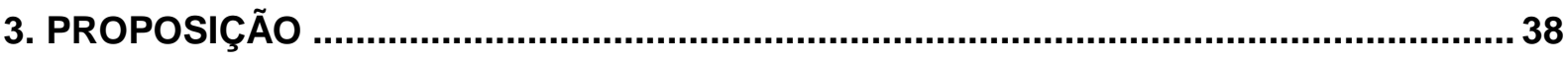

4. MATERIAL E MÉTODOS ................................................................................... 40

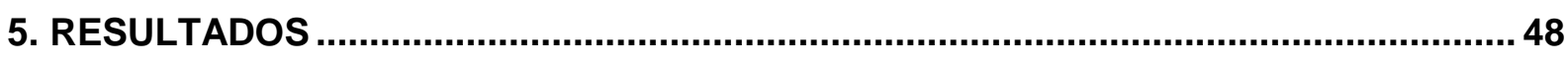

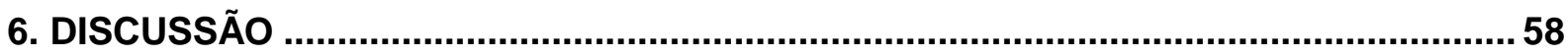

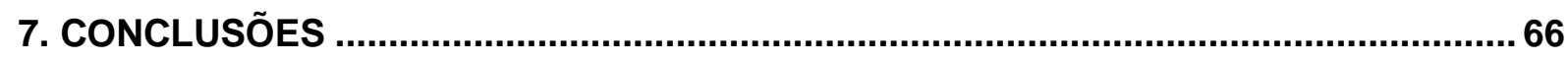



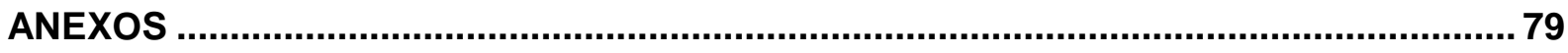





\section{RESUMO}

\section{SAVARIS C. Efeito das Reabilitações Bucais na Eficiência de Ciclos Mastigatórios -}

Análise Eletromiográfica por Meio da Integral da Envoltória. 2011. 82 p. Tese de Doutorado - Faculdade de Odontologia de Ribeirão Preto, Universidade de São Paulo, Ribeirão Preto, 2011.

A perda dental determina importantes alterações no sistema estomatognático, dentre elas, a redução da performance mastigatória, uma vez que esta é dependente das condições da dentição do indivíduo. Dessa forma, o restabelecimento da função tem grande importância em pacientes reabilitados com próteses bucais. No presente estudo, foram analisados indivíduos adultos reabilitados com diferentes tipos de próteses bucais, com o objetivo de verificar a influência do tipo de reabilitação protética na eficiência dos ciclos mastigatórios por meio da integral da envoltória da atividade eletromiográfica na mastigação habitual de amendoins e uvas passas e na mastigação não-habitual com Parafilme. Participaram desta pesquisa 50 indivíduos divididos em cinco grupos de acordo com o tipo de reabilitação protética. Cada grupo foi constituído por 10 indivíduos: Grupo I - portadores de implantes e coroas unitárias; Grupo II - portadores de Prótese Total maxilar e Overdenture mandibular sobre implantes; Grupo III - portadores de Prótese Total maxilar e mandibular; Grupo IV - portadores de Prótese Parcial Removível maxilar e mandibular e Grupo V - indivíduos dentados totais (grupo controle). Neste estudo a eficiência do ciclo mastigatório foi analisada por meio da integral da envoltória do sinal eletromiográfico (microvolts/segundo). Os sinais eletromiográficos foram obtidos na mastigação habitual de amendoins e de uvas passas sem sementes, durante vinte segundos e na mastigação não habitual de Parafilme $\mathrm{M}^{\circledR}$ durante dez segundos. Os dados da mastigação foram analisados usando ANOVA e Teste de Duncan $(p \leq 0,05)$. Os resultados evidenciaram menores valores eletromiográficos para indivíduos dentados totais em todas as condições clínicas avaliadas, 
seguido do grupo portador de implantes com coroas unitárias. Pode-se concluir que a eficiência dos ciclos mastigatórios foi influenciada pelo tipo de reabilitação protética bucal.

Palavras-chave: músculos mastigatórios, mastigação, eficiência mastigatória. 


\section{ABSTRACT}

\section{SAVARIS C. Effect of Oral Rehabilitation at the efficiency of Masticatory Cycles -}

Electromyographic Analysis by Means of Integral Envelopment. 2011. 82 p. Dissertation (PhD degree) - School of Dentistry of Ribeirão Preto, University of São Paulo, Ribeirão Preto, 2011.

The tooth loss causes important changes in the stomatognathic system, among them the reduction of masticatory performance, since this is dependent on the conditions of a person's teeth. Thus, the restoration of function has great importance in patients rehabilitated with oral implants. In this study, we analyzed adult individuals rehabilitated with different types of denture, with the objective of verifying the influence of prosthetic rehabilitation in the efficiency of the cycles by means of the integral of the envelope of EMG activity in the mastication of peanuts and raisins and non-habitual chewing with Parafilm. The sample was 50 individuals, divided into five groups according to the type of prosthetic rehabilitation. Each group comprised 10 individuals: Group I - patients with implants and crowns, Group II - patients with maxillary denture and mandibular overdentures on implants, Group III - patients with maxillary and mandibular denture Group IV - patients with Partial Denture Removable maxillary and mandibular and Group V - dentate subjects (control group). In this study the efficiency of the masticatory cycle was analyzed by the integral of the signal envelope EMG (microvolts / second). The signals were obtained in the mastication of peanuts and raisins without seeds, for twenty seconds and chewing Parafilm unusually for ten seconds. Data of chewing were analyzed using ANOVA and Duncan Test ( $p \leq 0.05)$. The results showed lower EMG values for individuals dentate in all clinical conditions assessed, followed by the group with implants with crowns. It can be concluded that the efficiency of the cycles was influenced by the type of oral prosthetic rehabilitation.

Key words: masticatory muscles, mastication, masticatory efficiency. 


\section{Sntradusãa}




\section{INTRODUÇÃO}

Ainda que exista uma constante preocupação da Odontologia com a prevenção das doenças que afetam a cavidade da boca, muitos indivíduos são acometidos de cárie e de doença periodontal, além de sofrerem acidentes e traumas que podem levar à perda de parte ou de todo o dente (SANTOS et al., 2008).

$\mathrm{Na}$ população brasileira a perda dos dentes continua sendo grave problema de saúde pública e esta perda, segundo estudos epidemiológicos, ocorre precocemente promovendo nos indivíduos, ainda muito jovens (faixa etária entre 15 e 19 anos), a necessidade de algum tipo de reabilitação protética. Com o passar da idade, a população continua apresentando perda dental e de acordo com o Ministério da Saúde (2004), 93\% dos indivíduos na faixa etária entre os 65-74 anos apresentam-se desdentados parciais e ainda, $75 \%$ desta população apresentam-se desdentados totais.

A perda do elemento dental resulta em importantes disfunções do sistema estomatognático, uma vez que, este sistema atua funcionalmente de forma integrada por meio de um conjunto de órgãos e tecidos, cuja morfologia e fisiopatologia são absolutamente interdependentes (GAVIÃO et al., 2001). Para atuar de forma harmônica necessita da organização e integração de seus constituintes: maxila, mandíbula, articulações temporomandibulares, arcos dentais, relação oclusal, língua e músculos (MONGINI, 1998). Trata-se de um sistema complexo que desempenha funções como fonação, deglutição e mastigação (GALO et al., 2006).

A disfunção do sistema estomatognático tem seu início com as agressões à anatomia dos elementos dentais, que podem evoluir e atingir as bases ósseas. Em situações onde avulsões dentais são indicadas, o processo alveolar tende a sofrer 
reabsorção, sem nova formação óssea, resultando desequilíbrio no arco dental. Observa-se que a mucosa de revestimento do arco dental apresenta número reduzido de receptores, diminuindo assim, a quantidade de impulsos aferentes ou sensitivos, que por sua vez, pode influenciar diretamente o controle e a atividade muscular peribucal, podendo ainda causar alterações nas articulações temporomandibulares (FIGÚN; GARINO, 1994; PIANCINO et al., 2005).

Uma das técnicas utilizadas para a análise das implicações de desordens funcionais na musculatura é a eletromiografia de superfície (EMG). Na Odontologia, as pesquisas com eletromiografia foram iniciadas em 1949, com Moyers, na tentativa de compreenderem o comportamento da musculatura frente ao desenvolvimento craniofacial.

A avaliação da atividade mioelétrica tem se constituído em uma importante ferramenta para a investigação das bases fisiopatológicas das alterações que acometem o desempenho da musculatura facial durante a mastigação (REGALO et al., 2006a). Os primeiros movimentos mastigatórios são incoordenados e evoluem ao longo da erupção dos dentes decíduos e permanentes, com a ação dos proprioceptores do periodonto e das articulações temporomandibulares, assim como com os sentidos do tato lingual e das mucosas. A função mastigatória, por meio da dinâmica mandibular fisiológica, propicia estímulos mecânicos adequados à cabeça da mandíbula e ligamento periodontal, principais meios de adaptação para o crescimento e desenvolvimento facial, assim como para a manutenção dos processos adaptativos, presentes por toda a vida (PLANAS, 1987; McNEILL, 2000). A aquisição do comportamento mastigatório promove alterações estruturais e funcionais subsequentes no esqueleto facial (ENLOW, 1993).

A análise da mastigação por meio da eletromiografia têm sido utilizada em diversos estudos (KASHIWAGl et al., 1995; BLANKSMA; VAN EIJDEN, 1995; HERMENS et al., 1999; BAZZOTTI, 1999; BUZINELLI; BERZIN, 2001; GONZALEZ et al., 2002; TOMIYAMA et al., 2004; SIÉSSERE et al., 2009; CECÍLIO et al., 2010) e os dados obtidos com estes trabalhos são considerados importantes fontes de informações clínica e cinesiológica na análise funcional do sistema estomatognático (GLAROS et al., 1997; RILO et al., 1997; 
MICHELOTTI et al., 1997; SGOBBI; BERZIN, 1998; BAZZOTTI, 1999; KARKAZIS, 2002; BERRETIN-FELIX et al., 2008; ANDRADE et al. 2009).

Em 1997, De Luca afirmou que havia necessidade de diminuir as influências das características não-estacionárias do sinal eletromiográfico nos resultados obtidos nas pesquisas com a técnica eletromiográfica, limitando a análise de sinais em contrações nãoisométricas repetitivas, como a mastigação, a períodos de sinal semelhantes aos observados em contrações isométricas. A análise da eficiência do ciclo mastigatório por meio da integral da envoltória do sinal eletromiográfico vem ao encontro à afirmativa de De Luca. A integral da envoltória do sinal eletromiográfico é uma medida matemática usada para avaliar desempenho e eficiência, e estabelecer comparações entre indivíduos em atividades dinâmicas, não estacionárias, como a mastigação (SIÉSSERE et al., 2009). Os dados obtidos permitem a análise da área sob a curva do sinal eletromiográfico dos ciclos mastigatórios e os valores obtidos são em microvolts/segundo. Segundo o SENIAM (European Recommendations for Surface Electromyography), que é o guia para reportar dados eletromiográficos publicado por Hermens et al., em 1999, esta é a melhor maneira de analisar eficiência de um processo fisiológico dinâmico como a mastigação. Apesar de estar de acordo com as regras internacionais propostas pelo SENIAM, esta forma de análise da função mastigatória ainda é uma forma inovadora de pesquisa, que traz inúmeras vantagens em relação ao método de peneiragem fragmentada, como a simplicidade, velocidade, precisão, reprodutibilidade, higiene, além de propiciar a mensuração de um grande número de amostras de maneira eficaz e rápida.

Atualmente, a análise eletromiográfica representa um meio não somente de diagnóstico, como também de avaliação e monitoramento de tratamentos realizados (REGALO et al., 2003; SANTOS et al., 2008), sendo possível registrar os potenciais de ação das fibras musculares e ainda, determinar como ocorre a coordenação dos músculos envolvidos na movimentação do sistema estomatognático (JANKELSON, 1990; MARCHIORI; VITTI, 1996; COOPER, 1997; CASTROFLORIO et al., 2008). 
As condições de hipertonicidade muscular resultam numa elevada atividade elétrica da musculatura afetada e o acompanhamento dessa atividade, por meio da eletromiografia, é uma forma insubstituível para compreender as condições fisiológicas ou patológicas do sistema estomatognático (COOPER, 1997). Trata-se de um procedimento seguro e eficaz que pode ser realizado em pacientes saudáveis ou disfuncionados, em adultos ou crianças (PANCHERZ, 1980; FERRARIO et al., 2002).

Com a crescente valorização do aspecto funcional do sistema estomatognático, o diagnóstico das maloclusões e a avaliação dos tratamentos não devem se restringir apenas ao exame clínico e radiográfico. Um tratamento somente é considerado integral se as relações forem estáveis e houver harmonia entre forma e função (DAWSON, 1993; FALTIN JÚNIOR et al., 2003).

A função mastigatória é um parâmetro objetivo que contribui na identificação do nível da capacidade de mastigação do indivíduo (TSUGA et al., 1998). Por sua vez, a função mastigatória pode ser influenciada pela eficiência mastigatória (CARAPITO, 2004).

A eficiência mastigatória fornece informações essenciais que podem colaborar em um diagnóstico apropriado a respeito da função mastigatória (OKIYAMA, 2003). Neste contexto as reabilitações bucais têm objetivos essenciais como devolver ao indivíduo uma mastigação eficiente, fonação apropriada, deglutição adequada e satisfação estética (ROSA, 2010). Entretanto, mesmo após a reabilitação bucal, muitos pacientes se queixam da perda de eficiência mastigatória (AKAGAWA et al., 1989; GOIATO et al., 2010; ROSA, 2010). Diante do exposto, fica clara a necessidade de investigar a eficiência mastigatória em indivíduos com diferentes tipos de reabilitações protéticas bucais. 
Q. Oevisãa da Ofirevauna 


\section{REVISÃO DA LITERATURA}

Esta pesquisa abrange dois tópicos básicos, aos quais se relacionou a revisão de literatura: Mastigação e Eficiência Mastigatória.

\subsection{MASTIGAÇÃO}

Uma das funções mais importantes do sistema estomatognático é a mastigação. Trata-se da primeira fase do processo digestório, sendo um ato rítmico e intermitente em que a língua, face e músculos da mandíbula agem em coordenação com a posição do alimento entre os dentes, corta-o e, em seguida, o prepara para a deglutição (LUND, WIDMER, 1989). Além disso, a mastigação está diretamente relacionada com a manutenção dos arcos dentais, com a estabilidade da oclusão e com o estímulo funcional, principalmente sobre o periodonto, músculos e articulações (MOLINA, 1989; KARKAZIS; KOSSIONI, 1997).

Conhecer e estabelecer os parâmetros relacionados com os ciclos mastigatórios é de grande importância para a Odontologia. Desta forma, em 1942, Kurth verificou que os métodos de análise que utilizavam aparatos que interferiram no controle inconsciente da mastigação poderiam levar a uma atividade consciente ou a um elemento de movimento voluntário do ciclo mastigatório invalidando as observações.

Ao analisar a função mastigatória de aborígines australianos, Beyron (1964) observou que os mesmos apresentavam mastigação bilateral e alternada, regulares, onde os movimentos de abertura e fechamento eram executados com poucos desvios da linha média e em lateralidade, os movimentos mastigatórios apresentavam grande amplitude. 
Ahlgren (1976) analisou em 35 crianças portadoras de maloclusões os padrões mastigatórios na mastigação de cenoura e goma classificando os ciclos mastigatórios encontrados em sete tipos diferentes: I - gota com o movimento de abertura medial; II - gota com o movimento de abertura contra-lateral ao plano sagital mediano; III - gota com o movimento de abertura lateral ao plano sagital mediano, todos os três tipos apresentavam ainda o movimento de fechamento lateral em relação ao movimento de abertura; IV - oito com um padrão vertical de movimento; V: reverso (o fechamento é medial em relação à abertura); $\mathrm{VI}$ - contra-lateral (com o movimento de abertura ocorrendo contralateralmente ao lado de mastigação e o movimento de fechamento próximo ao plano sagital); VII - irregular (com movimentos randomizados em relação ao padrão e ritmo). Verificou que os padrões mastigatórios nas crianças possuíam um perfil com características individuais. As crianças da classificação Tipo I a III, com oclusão normal, possuíam ciclos mastigatórios mais simples e com padrões mais regulares. As crianças portadoras de maloclusão (IV a VII) apresentaram ciclos mais complexos. O contato entre os dentes ocorreu em 95\% dos ciclos mastigatórios durante a mastigação de goma de mascar (com uma variação individual entre $40 \%$ e $100 \%$ dos ciclos) enquanto que com a mastigação de cenoura o contato dental ocorreu em $84 \%$ dos ciclos, o que demonstra a possibilidade de que os sistemas sensóriomotores bucais estivessem entre os fatores determinantes do comportamento da função mastigatória. O autor não evidenciou uma correlação entre os padrões dos ciclos mastigatórios registrados com o tipo de maloclusão.

Planas (1977) desenvolveu uma técnica de pistas diretas com o intuito de restabelecer o plano oclusal fisiológico, realizadas com resina foto-polimerizável na dentição decídua, que foi denominada de Técnica de Pistas Diretas Planas. A função das pistas era possibilitar o contato dental em trabalho e não-trabalho durante a mastigação bilateral alternada, onde esta condição de equilíbrio oclusal se tornava essencial para a manutenção e desenvolvimento adequados do sistema estomatognático.

A afirmativa de Shimidt, em 1979, de que o homem só pode produzir trabalho ou atuar sobre o meio ambiente por meio de seus músculos, é válida para o esforço físico e 
para as "atividades intelectuais", dentre elas o falar e o escrever, que exigem a funcionalidade de grupos musculares específicos.

Wickwire et al. (1981) avaliaram o padrão mastigatório normal em crianças com dentição decídua, mista e permanente. Verificaram que o padrão dos ciclos mastigatórios em crianças com dentição decídua é caracterizado por grandes excursões laterais durante o movimento de abertura bucal, sendo maior que a excursão lateral de fechamento. $\mathrm{Na}$ dentição mista ocorreu uma diminuição do movimento lateral de abertura e aumento da excursão lateral durante o fechamento mandibular. Por volta dos doze ou quatorze anos, dentição permanente, o padrão típico mudou completamente e, se caracterizou por um padrão de abertura sagital e fechamento lateral.

Beecher e Corruccini (1981) avaliaram a dieta com consistências alimentares diferentes no desenvolvimento do sistema mastigatório. Utilizaram noventa ratos de vinte e um dias de idade, os quais foram divididos em três grupos: grupo I, alimentado com dieta dura (ração granulada), grupo II, dieta macia (alimento moído misturado com água) e grupo III, alimentado por seis dias com dieta macia e a cada sete dias por grãos. A alimentação foi fornecida por quatro meses e posteriormente os animais foram analisados quanto a massa corpórea do músculo masseter, comprimento do arco maxilar, comprimento mandibular e antero-posterior da superfície condilar articular. Os resultados mostraram que os ratos que foram alimentados com dieta dura (grupo I), apresentaram maiores medidas de todas as dimensões, já o grupo com a alimentação alternada (grupo III), as medidas das estruturas analisadas mostraram-se intermediárias, mas mais próximas do grupo II.

Brandt e Rugh (1982) avaliaram o padrão mastigatório em seis crianças na faixa etária entre cinco e nove anos, com mordida cruzada posterior e verificaram que padrões mastigatórios considerados normais foram executados na maior parte das vezes no lado que não apresentava mordida cruzada.

Thexton (1982) verificou a programação da mastigação por meio de impulsos eferentes de circuitos neurais organizados (biofeedback), avaliando que após os estágios iniciais da primeira mordida, a mastigação apresenta modificações consideráveis por 
retroalimentação periférica proporcionada pelos contatos dentais. Afirmou que os impulsos sensoriais gerados durante o fechamento da mandíbula sobre o alimento asseguram a manutenção da atividade mandibular rítmica pelo fornecimento de impulso para as redes neurais osciladoras e por meio da modificação da programação central.

Ramfjord e Ash (1984) afirmaram que a mastigação bilateral, alternada e multidirecional, com atividade muscular sincrônica, é resultado de uma oclusão adequada, que possibilita a distribuição de forma homogênea do alimento sobre as superfícies dentais, com distribuição uniforme das forças mastigatórias nos tecidos de suporte dos dentes, possibilitando o que consideraram como função mastigatória ideal.

Carlsson (1984) concluiu que o estado da oclusão dental explicava a maioria dos casos de diminuição da eficiência mastigatória e, que a idade por si só tinha pouca influência neste fator. Verificaram que os indivíduos desdentados, na maior parte das vezes, não são considerados funcionais e mesmo quando reabilitados com as próteses totais, a eficiência mastigatória é muito menor do que a dos indivíduos com dentes naturais, com próteses fixas sobre os dentes naturais ou com implantes osteointegrados. Afirmaram que a manutenção de dentes naturais e saudáveis é a melhor forma dos indivíduos obterem uma eficiência mastigatória satisfatória, mesmo com o aumento da idade.

Christensen e Radue (1985) observaram a relação entre lado de preferência mastigatória e lado de preferência manual. Os pesquisadores avaliaram o lado de colocação do bolo alimentar durante mastigação habitual de goma por meio de inspeções visuais. Em cada uma das três séries de observações, não houve diferença significativa na colocação do bolo alimentar entre lado direito e esquerdo, sendo que o lado de preferência lateral na colocação do bolo alimentar acontecia ao acaso. Os dados informados pelo paciente sobre lado predileto de mastigação foram confiáveis, não podendo, porém, ser relacionado com o lado de preferência do uso da mão. O uso predominante de um lado de preferência mastigatória direita ou esquerda foi considerado uma expressão comportamental.

Hoogmartens e Caubergh (1987) verificaram que o lado de preferência mastigatória apresenta correlação significativa com o lado no qual o indivíduo realiza os primeiros ciclos 
mastigatórios. Evidenciaram que metade dos indivíduos possuíam um lado preferencial de mastigação para os lados esquerdo ou direito. Não foi verificado correlação entre lado de preferência mastigatória com a predominância no uso das mãos, pés, olhos e ouvido. Os investigadores concluíram que um mecanismo periférico proprioceptivo de modulação poderia ser responsável pela determinação do lado de preferência mastigatória, diferente do sistema cortical proposto como responsável pelos controles na dominância das mãos, pés, olhos e ouvido.

De acordo com Van Der Linden (1990), os tecidos moles internos e externos da face, assim como todos os componentes funcionais do sistema estomatognático, influenciam-se mutuamente e, de certo modo, competem entre si. Se existe um equilíbrio entre os fatores, a face se desenvolverá sem nenhuma mudança acentuada na sua configuração, nem rotação notável.

Moyers (1991) afirmou que a mastigação de alimentos duros e fibrosos provoca desgastes dentais fisiológicos, importantes para o desenvolvimento do sistema estomatognático, principalmente com relação à etiologia da maloclusão. O uso de dieta mais fibrosa estimula o trabalho muscular, aumentando consideravelmente a carga funcional sobre os dentes, produzindo menos cáries, maior média de largura dos arcos e um desgaste acentuado das faces oclusais dos dentes. Considerou que a dieta muito pastosa propiciou um aumento na etiologia das maloclusões e afirmou que a atrição fisiológica que ocorre no final da dentição decídua e início da dentição mista era necessária para a remoção de "interferências" cuspídicas que permitem a mandíbula assumir uma posição mais anterior e quando isto não ocorre, considerou desfavorável o estabelecimento de uma oclusão permanente fisiológica.

Segundo Ettala-Ylitalo e Laine (1991), durante a fase de crescimento das crianças, o ajuste oclusal é importante, pois o mesmo possibilita a reabilitação da atividade neuromuscular fisiológica, numa fase em que o controle motor ainda não está totalmente amadurecido, evitando a programação patológica ou alterada dos movimentos mastigatórios. 
Mahmood et al. (1992) determinaram à eficiência e a performance mastigatória de pacientes antes e após a colocação de próteses imediatas. A função mastigatória dos indivíduos com próteses imediatas foi comparada com a de indivíduos dentados e com indivíduos portadores de próteses totais. Verificaram que os indivíduos dentados apresentaram melhor eficiência mastigatória do que os pacientes com próteses totais ou com as próteses imediatas.

Wilding et al. (1992) realizaram uma pesquisa para verificar a influência da área de contatos dentais no lado de preferência mastigatória. Foram utilizadas imagens digitais do registro em cera durante o apertamento dental de trinta indivíduos. A técnica utilizada foi a transiluminação para se agrupar valores em categorias de densidades de cera pela área total de apertamento e depois foram calculados os contatos entre os dentes. Não foi verificado correlação entre a área de contato oclusal e a preferência mastigatória.

Wilding (1993) afirmou que a mastigação sofre influências de vários fatores, como os movimentos da mandíbula e da língua, a atividade dos músculos peribucais, a força de mordida e as superfícies oclusais, mas não esclareceu qual destes fatores é mais importante na eficiência da mastigação.

Mowlana e Heath (1993) avaliaram a mastigação de amendoins soltos e dentro de uma bolsa de borracha mastigável em indivíduos adultos saudáveis, divididos em dois grupos: um grupo mastigava amendoins soltos e o outro grupo mastigava os amendoins na bolsa. Verificaram que os resultados, quanto à distribuição do tamanho das partículas foram similares. A mastigação com as bolsas pareceram mais aceitáveis aos participantes da pesquisa e eliminaram o fator perda de partículas que ocorre na técnica convencional. Um sistema de escaneamento óptico foi utilizado permitindo facilidade e rapidez na medida das partículas.

Segundo Marchesan (1993), durante o ato mastigatório, vários grupos musculares contraem-se coordenadamente, assim como os músculos da língua e os músculos faciais, destacando neste processo os músculos bucinador e o orbicular da boca. 
Felício (1994) afirmou que algumas maloclusões podem ser oriundas por mastigação insuficiente, maus hábitos e postura alimentar inadequada.

Kazazoglu et al. (1994) avaliaram os sete ciclos iniciais de indivíduos parcialmente dentados e desdentados totais. Concluíram que um lado de preferência ocorria na maioria dos indivíduos (60\%). Verificaram uma forte correlação entre o lado de preferência observado e o lado no qual o paciente acredita ser seu preferido (75\%). Algumas variações ocorreram somente no primeiro ciclo, talvez devido à forma inicial do bolo alimentar, porém os outros ciclos consecutivos foram realizados todos do lado de preferência mastigatória.

Mowlana et al. (1994) validaram o sistema óptico por comparação com o peneiramento utilizando como alimento teste o amendoim. A eficiência mastigatória foi verificada em indivíduos dentados completos. Os alimentos foram mastigados uma, quatro, oito, dezesseis e trinta e duas vezes. Os resultados de ambos os métodos foram descritos pela distribuição do tamanho das partículas baseada no volume das mesmas e foram similares, evidenciando que o uso do método óptico é eficiente e por ser um método de escolha simples, rápido e facilmente aplicável em análises mastigatórias.

Kiliaridis (1995) verificou o treino mastigatório correlacionados à força e resistência à dos músculos mastigatórios. O grupo experimental mastigou uma goma dura especial, por uma hora diária, durante vinte e oito dias. Registrou-se a máxima força e a duração de mordida antes e após o experimento. Observou que após o treino, houve aumento significativo no grupo experimental, em relação à máxima força de mordida. $\mathrm{O}$ autor concluiu que exercícios mastigatórios sistemáticos podem levar a aumento significativo da força mastigatória

Hanson e Barret (1995) observaram que a oclusão normal que ocorre durante o ato mastigatório e na deglutição é essencial para manter a vitalidade do sistema mastigatório. Os músculos da língua, intrínsecos e extrínsecos e os supra-hioídeos, atuam quando o bolo alimentar é posicionado e impulsionado, assim como os músculos da mastigação, que mantém os dentes em forte oclusão, desempenhando a função com maior estabilidade 
mecânica, fortalecendo a musculatura antigravitacional, estimulando o posicionamento correto dos dentes e incentivando a formação de osso alveolar.

Julien et al. (1996) estudaram a mastigação e a eficiência mastigatória de adultos e crianças, de ambos os sexos, por meio de peneiras, utilizando um alimento padronizado, o Cuttersil. Os resultados evidenciaram uma diferença significativa no desempenho mastigatório entre os dois grupos avaliados. Os homens adultos foram mais eficientes, seguidos pelas mulheres e depois às crianças, sendo que nestas os resultados foram semelhantes entre meninos e meninas.

Poikela et al. (1997) analisarm os efeitos da função mastigatória unilateral no crescimento crânio-facial em coelhos, após desgastes dos dentes superiores e inferiores de hemiarcos antagonistas até o nível gengival e verificaram que a função mastigatória unilateral foi o fator determinante do crescimento crânio-facial assimétrico.

Para Branam e Mourino (1998), a correção da maloclusão em crianças com mordida aberta anterior melhora o fluxo aéreo nasal, a oxigenação tecidual e contribuí para a eliminação da respiração bucal. Verificaram que incrementando com resina a face oclusal de molares decíduos em caso de mordida profunda, ocorria uma redução ou eliminação de otite média, devido à nova posição mandibular, com reposicionamento da língua e musculatura da orofaringe que mantêm a tuba auditiva fechada durante a deglutição, espirro e bocejo, impedindo que saliva e secreção penetrem por ela. Concluíram que a relação entre oclusão e otite média ainda não está claramente estabelecida necessitando mais estudos.

Henrikson et al. (1998) avaliaram a eficiência e a habilidade mastigatória de jovens do sexo feminino, com oclusão normal e maloclusão de classe II, dessa forma, associando eficiência e habilidade mastigatória com sinais e sintomas de disfunções temporomandibulares. Os autores concluíram que a eficiência e a habilidade mastigatória eram, parcialmente, dependentes da oclusão e que, os sintomas de disfunção temporomandibular influenciaram a eficiência e a habilidade.

Simões (1998) observou que a atividade neuromuscular é o resultado dos contatos dentais e verificou que para os indivíduos apresentarem estabilidade oclusal é necessário 
mastigar dos dois lados, um de cada vez, e protruir durante a incisão. O equilíbrio endócrino, a dieta adequada e o exercício preservam a forma e a função óssea. A função mastigatória adequada contribui significativamente para o desenvolvimento do sistema mastigatório e a mastigação bilateral e alternada, favorece o crescimento e desenvolvimento do complexo maxilomandibular, mantendo o mesmo com uma forma adequada que propicia um melhor desempenho das funções orais.

Van Der Laan (1998) avaliou a função mastigatória em indígenas lanomâmis e verificou que a dinâmica mandibular e a função mastigatória $(89,5 \%)$ são balanceadas bilateralmente e com ampla liberdade dos movimentos mandibulares em lateralidade. Concluiu que a fisiologia e biofísica da mastigação habitual do ser humano é importante para a compreensão do desenvolvimento natural do sistema estomatognático, sua oclusão e função.

Mioche et al. (1999) analisaram o padrão de atividade dos músculos masseter e temporal durante a mastigação de diferentes tipos de alimentos e determinaram a variabilidade interindividual. Para tanto, utilizaram a eletromiografia em 36 adultos jovens durante a mastigação habitual e não-habitual. Observaram que ambos os músculos masseter e temporal tiveram aumento da atividade com o aumento do estresse na trituração dos alimentos mastigados. Concluíram que o processo mastigatório é ajustado para acomodar a textura dos alimentos.

McNeill (2000) verificou que para melhorar a harmonia funcional mastigatória e a deglutição, a minimização das forças oclusais traumáticas promovem a estabilidade estrutural do sistema estomatognático, principalmente por otimizarem a distribuição das forças oclusais. O autor considerou que a harmonia funcional pode ser obtida com 0 redirecionamento dos contatos guia ou eliminação dos contatos deflectivos proporcionando movimentos excursivos mandibulares suaves em todos os planos de referência, devolvendo a homeostase entre os tecidos que interagem dentro do sistema estomatognático com os fatores ambientais locais trazendo equilíbrio funcional para os dentes, tecidos de suporte, sistema neuromuscular e articulações temporomandibulares. 
Para Ogawa et al. (2001), a teoria de que as respostas motoras do sistema mastigatório em função dos estímulos periféricos se alteram de acordo com o potencial funcional dos indivíduos é verdadeira. Os autores afirmaram que devem ser consideradas as características individuais para identificação do efeito dos estímulos periféricos na função mastigatória humana.

Oliveira (2002) afirmou que a mastigação bilateral alternada é importante como fator para a homeostase do sistema mastigatório, evitando o crescimento assimétrico das estruturas de suporte, hipertrofia muscular, sobrecarga de dentes e periodonto do lado de preferência mastigatória além de remodelamentos adaptativos da articulação temporomandibular. Mesmo havendo inúmeras controvérsias sobre a correlação entre fatores oclusais e disfunções temporomandibulares, salientou que a maloclusão é um dos fatores etiológicos das disfunções temporomandibulares, juntamente com fatores neuromusculares e psicogênicos.

Mizumori et al. (2003) avaliaram a influencia da textura do alimento duros e moles na lateralidade do movimento mastigatório em dez sujeitos saudáveis, com idade entre vinte e quatro e vinte e oito anos, de ambos os sexos, sem sinais de disfunção temporomandibular. Diferenças significativas foram verificadas entre os alimentos mais duros e os mais moles. Os alimentos mais duros provocam maior lateralidade mandibular.

Para Hayasaki et al. (2003), a mastigação é uma das funções mais importantes do sistema estomatognático, mas existem poucos estudos na literatura em crianças. Avaliaram a mastigação de goma de mascar em crianças e verificaram que as mesmas possuem um padrão mastigatório característico que difere dos adultos.

Pignataro Neto et al. (2004) avaliaram eletromiograficamente os músculos masseteres durante mastigação habitual de cenoura e Parafilme, correlacionando estes dados com a inspeção visual, para observarem qual era o lado de preferência mastigatória de vinte e nove indivíduos na faixa etária entre dezoito e vinte e cinco anos. Consideraram a presença de um lado de preferência mastigatória quando os valores de amplitude de contração muscular tivessem uma diferença de pelo menos $20 \%$ entre os músculos 
masseteres direito e esquerdo, assim como quando a mastigação ocorria com uma frequência de ciclos mastigatórios, pelo menos 30\% maior para um dos lados, após o registro de vinte ciclos mastigatórios consecutivos. A concordância entre a eletromiografia e a inspeção visual foi verificada em $83 \%$ das análises.

As doenças bucais mais comuns em idosos são a perda de dentes, principalmente por doença periodontal, a cárie e o câncer bucal, associadas ao envelhecimento dos tecidos e funções orais. Segundo Kossioni e Dontas (2007) a presença de pelo menos vinte dentes na cavidade da boca resulta em dificuldades mastigatórias. A perda do dente leva a uma diminuição da performance mastigatória e consequentemente leva os indivíduos a uma dieta pastosa, pobre em fibras e rica em gordura saturada.

Goiato et al. (2008) avaliaram a atividade eletromiográfica dos músculos masseter e temporal em indivíduos com severa reabsorção óssea em dois momentos distintos: (a) o período inicial, com as próteses que usavam há mais de 10 anos, e (b) o período final, cinco meses depois de ter novas próteses colocadas em uso clínico. A atividade dos músculos foi registrada durante a mastigação de um alimento artificial (Optocal) durante 35 ciclos mastigatórios. Após o uso das dentaduras novas por cinco meses, o músculo temporal direito mostrou uma diferença estatisticamente significativa antes e após a reabilitação de prótese no início e no final da mastigação. Observaram ainda que, a atividade eletromiográfica do músculo masseter foi reduzida após a reabilitação.

Magalhães et al. (2010) realizaram uma revisão sistemática da relação entre maloclusão, performance mastigatória, além da análise qualitativa da solidez metodológica dos estudos disponíveis na literatura. As deficiências mais graves observadas nos ensaios clínicos foram amostras muito pequenas de sujeitos de pesquisa, descrição inadequada dos critérios de seleção, falta de método de análise de erros e falta de cegueira em medições. Os autores afirmaram que as maloclusões causam diminuição da performance mastigatória, especialmente no que se refere à redução da área de contatos oclusais. 


\subsection{EFICIÊNCIA MASTIGATÓRIA}

A avaliação dos movimentos mandibulares é de fundamental importância na área da Odontologia. Os padrões de movimentação deveriam ser considerados em conjunto com a articulação mandibular, com o sistema de articulações sinoviais, com os músculos e com as estruturas associadas, quando houvesse uma suspensão dos movimentos normais da mandíbula (BROWN, 1975).

A forma do ciclo mastigatório, tanto na dentição natural quanto em próteses, após a mastigação de vários tipos de alimentos foi descrita por Bates et al. (1976). Num mesmo indivíduo, o padrão do ciclo mastigatório apresentou poucas variações, porém entre indivíduos o padrão variou bastante, sendo influenciado pela oclusão, pela consistência, tipo, tamanho e textura do bolo alimentar. Estes pesquisadores verificaram que os indivíduos mastigam pelo lado no qual ocorre o maior número de contatos dentais sendo que, se estes forem iguais dos dois lados, a mastigação será bilateral alternada e o bolo alimentar movido de um lado para o outro de forma consistente e regular.

O padrão mastigatório também foi estudado por Gibbs et al. (1982) comparando-o entre crianças com dentição decídua, mista e permanente, e adultos. Estes pesquisadores verificaram que a mastigação em adultos e crianças com oclusão normal caracterizava-se pelo contato dental, pausa na posição de intercuspidação máxima e amplos movimentos laterais. O padrão mastigatório em crianças com dentição decídua caracterizava-se por amplos movimentos laterais na abertura (maior que o de fechamento). Com o aumento da idade, o padrão se alterava caracterizado pela abertura medial e amplo movimento lateral de fechamento bucal. Verificaram também que alimentos de consistência mais dura provocavam excursões laterais mais amplas nos adultos e mais mediais nas crianças.

Tzakis et al. (1989) avaliaram a influência de um treino mastigatório no aumento da eficiência mastigatória. Os indivíduos executaram o treino mastigatório por uma hora, durante vinte e oito dias. A porcentagem de eficiência mastigatória foi medida com um 
sistema especial de peneiras ou tamises, e dez ciclos mastigatórios registrados por meio de eletromiografia. O treino não influenciou de maneira significativa a eficiência mastigatória.

Segundo Miyauchi et al. (1989), a oclusão é o fator mais importante na influência do movimento mastigatório. Verificaram que em indivíduos portadores de mordida cruzada posterior, a eficiência dos ciclos mastigatórios normais foram menos frequentes do que no grupo com oclusão normal.

Tzakis et al. (1992) avaliaram a função mastigatória de doze pacientes portadores de disfunção temporomandibular muscular antes e após tratamento e verificaram que após o tratamento a eficiência mastigatória aumentou de $54 \%$ para $65 \%$. Concluíram que a função muscular do sistema estomatognático estava comprometida e que o tratamento teve um efeito positivo sobre a função mastigatória.

A comparação da eficiência mastigatória de um grupo de indivíduos com perda, em média, de seis dentes posteriores e, de um grupo controle com dentição completa mostrou que a média do número de ciclos mastigatórios para o preparo do bolo alimentar para deglutição era significativamente maior para os participantes do grupo experimental do que para o grupo controle. Mostrou também que não havia correlação entre a eficiência mastigatória e o número de ciclos mastigatórios dentro dos grupos estudados (VAN DER BILT et al., 1993).

Em 1997, De Luca afirmou que a análise da eficiência e do desempenho do ciclo mastigatório deveria ser feita por meio da integral da envoltória do sinal eletromiográfico.

Youssef (1997) determinou as diferenças entre sexos durante a mastigação, por meio da análise da atividade eletromiográfica dos músculos masseter e temporal. Este pesquisador verificou que os homens apresentavam ciclos mastigatórios mais curtos, maior velocidade e maior força mastigatória, quando comparados às mulheres.

De acordo com Yamashita et al. (1999) a parte mais importante do ciclo mastigatório está próxima da máxima intercuspidação onde os contatos deslizantes ocorrem. Para estes autores, não existia um padrão mastigatório ideal que pudesse ser usado clinicamente ou 
em pesquisas que garantisse a saúde do sistema mastigatório e nem que predissesse a eficiência mastigatória.

O ciclo mastigatório é um movimento funcional intimamente relacionado à oclusão, ao sistema neuromuscular e ao sistema nervoso central (KIM et al., 2001). Segundo Papargyriou et al. (2000) o padrão dos ciclos mastigatórios varia durante o crescimento, sendo possivelmente decorrentes das modificações anatômicas, desenvolvimento do sistema nervoso e alteração das demandas funcionais.

A função mastigatória, definida como eficiência mastigatória, tem sido muitas vezes medida pela determinação da capacidade de um indivíduo de moer ou triturar determinado alimento e muitos fatores podem influenciar o desempenho do sistema mastigatório, tais como: perda dos dentes, restaurações nos dentes posteriores, força de mordida, idade e sexo, contatos oclusais e função motora (VAN DER BILT, 2002).

O movimento mandibular durante os movimentos de abertura, fechamento da boca, assim como os movimentos de mastigação em indivíduo de três anos e dez meses (dentição decídua), portadores de mordida cruzada posterior unilateral foi analisado por Saitoh et al. (2002). Exames foram realizados antes e após o tratamento corretivo para mordida cruzada, assim como após o período de contenção, sugerindo que o tratamento ortodôntico melhorou tanto a morfologia, quanto a função dos indivíduos.

A influência da idade na habilidade dos indivíduos adaptarem o sistema mastigatório a dureza dos alimentos foi estuda por Peyron et al. (2004). O estudo foi realizado em sessenta e sete voluntários com idade entre vinte e cinco a setenta e cinco anos, todos com dentição completa, sendo vinte e nove homens e trinta e oito mulheres. Estes pesquisadores verificaram que, com o aumento da idade, o número de ciclos mastigatórios aumentava para o mesmo alimento a ser triturado, porém a capacidade de adaptação do sistema estomatognático era grande e as funções se mantinham.

Em 2005, Piancino et al. estudaram a coordenação neuromuscular dos músculos masseter e temporais durante a mastigação, em mulheres de 24 anos, com oclusão normal. Durante os ciclos mastigatórios a atividade eletromiográfica era mais elevada no músculo 
masseter homolateral ao lado de mastigação do que no músculo contralateral, enquanto que nos músculos temporais as atividades eletromiográficas eram similares. Na comparação da mastigação de um bolo alimentar duro versus um bolo alimentar macio, a atividade durante a mastigação do bolo alimentar duro foi maior no músculo masseter contralateral que a do músculo masseter homolateral, indicando o equilíbrio neuromuscular do sistema estomatognático e a sua capacidade de se adaptar a diferentes cargas mastigatórias.

Regalo et al. (2006a) afirmaram que a eletromiografia é um importante instrumento para a investigação das bases fisiopatológicas das alterações que acometem o desempenho da musculatura facial durante a mastigação.

Segundo Peyron e Woda (2006) a idade exerce um papel importante nos indivíduos mais idosos, onde a percepção era diminuída e, consequentemente levavam mais tempo para reagir. Se suas dentições estavam relativamente completas e saudáveis, precisavam simplesmente de aumentar o número de ciclos mastigatórios para uma determinada quantidade de alimento e quanto mais duro era o alimento maior era o número de ciclos mastigatórios.

Para Zhao e Monahann (2007) os resultados funcionais do sistema estomatognático podem ser mensurados de diversas maneiras, principalmente por meio da análise do padrão do ciclo mastigatório e consequentemente pela eficiência mastigatória.

Em 2008, Mishellany-Dutour et al. avaliaram o impacto da idade e da dentição na função mastigatória. Estes autores verificaram que indivíduos idosos dentados utilizavam maior número de ciclos mastigatórios para chegar ao limiar de deglutição dos alimentos do que os indivíduos mais jovens, com o tamanho das partículas de alimento menores, sequências mastigatórias mais longas, e maior atividade eletromiográfica tanto para amendoins quanto para cenouras. Verificaram também, que indivíduos usuários de próteses totais utilizavam maior número de ciclos mastigatórios para chegar ao limiar de deglutição de amendoins do que indivíduos idosos dentados. As partículas de alimentos eram maiores, apesar do maior número de ciclos mastigatórios, maior tempo de duração da seqüência mastigatória e maior atividade eletromiográfica. A função mastigatória foi, portanto, 
adaptada ao envelhecimento, mas foi prejudicada nos usuários de próteses totais, onde os seus aparelhos protéticos não se adaptavam perfeitamente ao aparelho mastigatório deficiente.

O processo de mastigação deve ser entendido pelos cirurgiões-dentistas, visto que uma dentição adequada pode contribuir com o estado geral de saúde e bem estar dos indivíduos, como também auxiliar na conduta clínica e tratamento dos indivíduos que apresentam dentição comprometida (ORCHARDSON; CADDEN, 2009).

Mendonça et al. (2009) compararam a eficiência mastigatória em função dos ciclos mastigatórios de indivíduos dentados, reabilitados com próteses totais convencionais e com próteses totais inferiores implantossuportadas. Utilizaram alimento artificial e verificaram diferenças na eficiência mastigatória entre os diferentes grupos. Os autores verificaram que a maior eficiência mastigatória foi desenvolvida no grupo dos indivíduos reabilitados com prótese total inferior implantossuportada.

Vianna-Lara et al. (2009) compararam a eletromiografia de superfície dos músculos masseter e temporal nos diferentes padrões faciais, concluindo que os diferentes tipos de padrão facial vertical não determinam padrões distintos na atividade eletromiográfica, durante o repouso e mastigação bilateral.

Entretanto, segundo Gomes et al. (2010) a morfologia dentofacial pode afetar funções orofaciais como a função mastigatória, a área de contato oclusal e atividade dos músculos mastigatórios. Em seu estudo, avaliaram setenta e oito indivíduos que foram divididos em três grupos de acordo com o padrão facial vertical: 1. mesofacial, 2. braquifacial e 3. dolicofaciais. A eficiência mastigatória foi significativamente maior no braquifacial e menor em indivíduos dolicofaciais. Braquifaciais apresentaram a maior área de contato oclusal $\left(\mathrm{mm}^{2}\right)$, seguido por meso e indivíduos dolicofaciais. A eletromiografia dos músculos masseter e temporal mostrou que indivíduos dolicofaciais possuem os menores valores de atividade muscular, enquanto indivíduos braquifaciais apresentaram medidas significativamente mais elevadas. Concluíram que a morfologia craniofacial afeta a função 
mastigatória, área de contato oclusal e atividade eletromiográfica dos músculos mastigatórios.

Ap Biasotto-Gonzalez et al. (2010) compararam pela eletromiografia a atividade dos músculos masseter, temporal e supra-hióideos, durante a mastigação de diferentes materiais em indivíduos com oclusão normal, sem história de desordem craniomandibular, mostrando que o parafilme e o rolete de algodão apresentaram menor coeficiente de variação, sendo considerados como melhores materiais para serem utilizados nos estudos eletromiográficos na condição clínica de mastigação. 
3.@roposisc̃̃o 


\section{Proposição}

Analisar a eficiência de ciclos mastigatórios por meio da integral da envoltória do sinal eletromiográfico obtido dos músculos masseter e temporal em indivíduos portadores de diferentes reabilitações protéticas bucais considerando:

- Avaliação da mastigação habitual (amendoins e uvas passas sem sementes),

- Avaliação da mastigação não-habitual (Parafilme). 


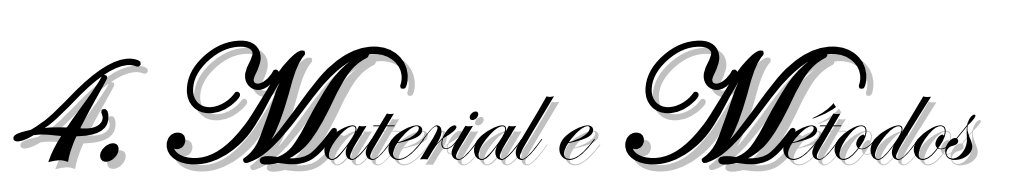




\section{Material e Métodos}

\section{Seleção da amostra (Voluntários da Pesquisa)}

Participaram desta pesquisa, voluntários com reabilitações protéticas bucais que procuraram tratamento na Clínica de Odontologia do Programa Brasil Sorridente, na Clínica de Especialização em Prótese Dentária da FORP-USP e, em duas clínicas odontológicas particulares de Ribeirão Preto. De 250 voluntários examinados, seguindo os critérios de inclusão e exclusão, foram selecionados 50 indivíduos com idade entre 35 a 70 anos, divididos em cinco grupos:

- Grupo I - constituído por 10 indivíduos reabilitados com no mínimo 10 implantes com coroas unitárias;

- Grupo II - constituído por 10 indivíduos reabilitados com Prótese Total maxilar e Overdenture sobre implantes mandibular;

- Grupo III - constituído por 10 indivíduos reabilitados com Prótese Total maxilar e mandibular;

- Grupo IV - constituído por 10 indivíduos reabilitados com Prótese Parcial Removível maxilar e mandibular;

- Grupo V - constituído por 10 indivíduos dentados (Dentados Totais - grupo controle). Todos os voluntários foram orientados sobre os propósitos e etapas da pesquisa e assinaram o Termo de Consentimento Livre e Esclarecido, previamente aprovado pelo Comitê de Ética em Pesquisa da FORP/USP (Processo n²008.1.167.58.3) de acordo com a resolução 196/96 do Conselho Nacional de Saúde. 
A seleção da amostra e os critérios de inclusão/exclusão dos voluntários foram determinados por meio de anamnese, exames clínicos e exames radiográficos. $\mathrm{Na}$ anamnese foram obtidas informações referentes aos dados pessoais, histórico médico, histórico dental, presença de hábitos parafuncionais e possíveis sintomas de disfunção temporomandibular (questionário RDC/TMD). Os itens utilizados como critérios de exclusão, durante a anamnese, foram:

- Portadores de próteses insatisfatórias clinicamente;

- Tempo de reabilitação bucal menor que um ano;

- Indivíduos que não apresentassem mastigação molar bilateralmente alternada;

- Presença de distúrbios de origem sistêmica ou local (DTM) que pudessem comprometer o sistema mastigatório, como distúrbios neurológicos, paralisia cerebral, entre outros;

- Utilização de medicamentos que pudessem interferir na atividade muscular, direta ou indiretamente, como anti-histamínicos, sedativos, xaropes, homeopatia ou outras drogas depressoras do Sistema Nervoso Central;

- Realização de tratamentos que pudessem interferir na atividade muscular, direta ou indiretamente, durante o período da realização da pesquisa, como tratamento ortodôntico, terapia fonoaudiológica e tratamento otorrinolaringológico.

\section{Eletromiografia na Mastigação}

A avaliação da eficiência de ciclos mastigatórios, proposta no protocolo desta pesquisa, foi realizada por meio de registros eletromiográficos dos músculos masseter e temporal, de ambos os lados, durante a mastigação habitual de alimentos duros $(3 \mathrm{~g}$ de amendoim) e macios ( $3 g$ de uvas passa) por vinte segundos e mastigação molar bilateral não-habitual de Parafilme durante dez segundos. Foi obtido também o apertamento dental 
máximo voluntário durante quatro segundos, sendo que, esta condição clínica foi utilizada como fator de normalização dos dados da amostra.

$\mathrm{Na}$ coleta dos dados eletromiográficos foi utilizado o Eletromiógrafo MyoSystem BR-1, versão portátil (Figura 1A), acoplado a um computador, com uma bateria própria. eletromiógrafo é constituído por doze canais, sendo oito canais para eletromiografia (para eletrodos ativos e passivos), quatro canais auxiliares, sistema de aquisição de dados de alta performance e software para controle, armazenamento, processamento e análise de dados. Os conectores possuem saídas de tensão CC de $\pm 12 \mathrm{~V} @ \pm 100 \mathrm{~mA}, \mathrm{CMRR}$ (relação de rejeição em modo comum) de $112 \mathrm{~dB} @ 60 \mathrm{~dB}$, impedância de entrada para eletrodos passivos $10^{10} \mathrm{Ohms} / 6 \mathrm{pf}$, correntes bias de entrada para eletrodos ativos de $\pm 2 \mathrm{nA}$, proteção contra sobretensões e filtros passa faixa para eliminação de ruídos de $5 \mathrm{~Hz}$ a $5 \mathrm{KHz}$.

Foram utilizados eletrodos ativos simples diferenciais, com dois contatos de prata de 10,0 x 1,0 mm e distância de 10,0 mm entre eles, fixos em um encapsulamento de resina de 40x20x5 mm (Figura 1B). Também foi utilizado um eletrodo circular de aço inoxidável, com três centímetros de diâmetro, como eletrodo de referência (eletrodo terra), o qual foi posicionado sobre a pele da região do osso frontal do indivíduo (Figuras 1C e 1D-I).

Os eletrodos foram posicionados sobre os músculos masseter (Figura 1D-II) e temporal (Figura 1D-III) seguindo as recomendações de Cram et al., 1998: o local mais adequado para a colocação dos eletrodos de captação é a região intermediária entre o centro da zona de inervação (ponto motor) e o tendão do músculo, alinhados longitudinalmente e paralelos ao sentido das fibras musculares. Para garantir a localização dos músculos, foi realizada manobra específica de contração voluntária máxima.

Previamente à colocação dos eletrodos, a pele dos voluntários foi limpa com álcool, com a finalidade de eliminar resíduos de gordura ou poluição, que eventualmente estivessem presentes e pudessem interferir nos resultados, além de tricotomia quando necessário. 

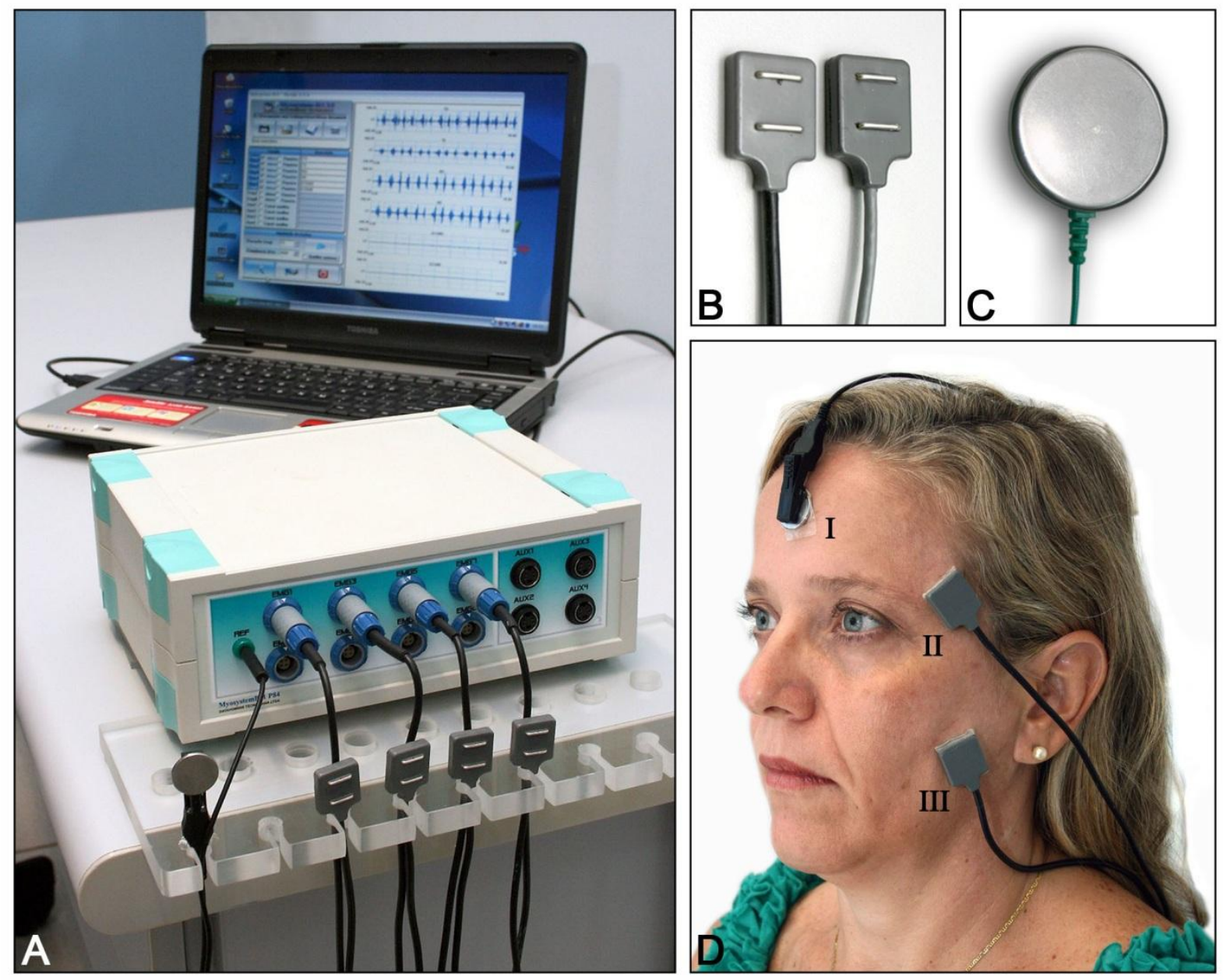

Figura 1: (A) Eletromiógrafo MyoSystem - BR1.

(B) Eletrodo ativo diferencial de superfície.

(C) Eletrodo de referência circular em aço inoxidável (terra).

(D) Eletrodo de referência em posição (I) e de superfície colocados sobre o ventre muscular do masseter (II) e do temporal (III). 
Os voluntários desta pesquisa foram orientados antes da realização de cada experimento, fornecendo instruções e esclarecendo eventuais dúvidas quanto ao procedimento, solicitando sempre que o mesmo permanecesse o mais calmo possível, respirando lenta e pausadamente.

Durante o registro eletromiográfico, manteve-se um ambiente calmo, silencioso, e o voluntário permaneceu sentado em uma cadeira confortável, com postura ereta, com as plantas dos pés apoiadas no solo, e as mãos apoiadas nas sobre as coxas. A cabeça foi posicionada de forma ereta, tendo o plano de Frankfourt paralelo ao solo, onde o voluntário se manteve olhando para o horizonte (Figura 2A).

\section{Aquisição dos dados eletromiográficos}

Neste estudo a eficiência do ciclo mastigatório foi analisada por meio da integral da envoltória do sinal eletromiográfico, sendo este valor em microvolts/segundo, durante a unidade de tempo. Os sinais eletromiográficos foram obtidos na mastigação habitual de alimento duro ( $\mathrm{g}$ de amendoins) e de alimento macio ( $\mathrm{g}$ de uvas passas), durante vinte segundos (Figura 2B e 2C). A eficiência do ciclo mastigatório também foi analisada na mastigação não-habitual contínua de um material inerte durante dez segundos. Este material inerte constitui-se em uma folha de parafina (Parafilme $\mathrm{M}^{\circledR}$ ) que foi dobrada $(18 \times 17 \times 4 \mathrm{~mm}$, peso $245 \mathrm{mg})$ e colocada sobre a face oclusal dos pré-molares e molares de ambos os lados da arcada dental (Figura 2D e 2E).

O valor da integral da envoltória obtido na condição clínica de apertamento dental máximo voluntário, colhido por quatro segundos foi utilizado para a normalização dos dados.

A normalização do sinal eletromiográfico é necessária para estabelecer comparações entre diferentes voluntários ou diferentes dias de coletas, sendo uma tentativa de reduzir as diferenças entre os registros de um mesmo voluntário, ou de voluntários diferentes de forma a tornar a interpretação dos dados reprodutíveis (Regalo et al., 2008). 




Figura 2: (A) Posição do voluntário no momento do exame.

(B) Alimento de consistência dura- amendoins.

(C) Alimento de consistência macia - uvas passas sem sementes.

(D) Folha de parafina (Parafilme $\mathrm{M}^{\circledR}$ ).

(E) Folha de parafina dobrada $\left(18 \times 17 \times 4 \mathrm{~mm}\right.$, peso $245 \mathrm{mg}$-Parafilme $\left.\mathrm{M}^{\circledR}\right)$. 


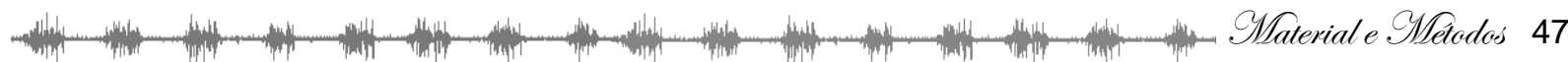

\section{Análise dos dados}

Os sinais eletromiográficos foram processados no programa Myosystem - Br1 versão 3.56. Após a digitalização, os sinais foram analogicamente amplificados (com um ganho de 1000x), filtrados (filtro passa-banda de $0,01-1,5 \mathrm{kHz}$ ) e amostrados por uma placa conversora A/D de 12 bites com freqüência de aquisição de $2 \mathrm{KHz}$.

Os dados eletromiográficos normalizados foram tabulados e submetidos à análise estatística utilizando o software SPSS versão 17.0 para Windows (SPSS Inc.; Chicago, IL, USA). Foi realizada a análise descritiva (médias, desvios padrão, valor máximo e valor mínimo) para cada variável. Os valores obtidos foram comparados pela análise de variância (ANOVA) e pelo teste complementar de Duncan. 
5. Resullades 


\section{Resultados}

\section{1- Resultados na Condição Clínica de Mastigação de Amendoins}

Durante a condição clínica habitual de mastigação de amendoins, houve diferença estatisticamente significativa entre os grupos analisados para o músculo masseter esquerdo e temporal esquerdo $(p<0,05)$. As médias eletromiográficas normalizadas dos músculos masseter direito e esquerdo mostraram maior atividade eletromiográfica no Grupo IV, portadores de prótese parcial removível maxilar e mandibular. Para o músculo temporal direito, as médias eletromiográficas normalizadas revelaram maior atividade muscular para o Grupo II, portadores de prótese total maxilar e overdenture mandibular. Entretanto, para o músculo temporal esquerdo, as médias eletromiográficas normalizadas foram maiores para - Grupo III, portadores de prótese total maxilar e mandibular. O Grupo V (controle), dentados totais, apresentou menores médias eletromiográficas normalizadas para todos os músculos avaliados (Figura 3 e Tabela 1). O teste complementar de Duncan pode ser verificado na Tabela 2.

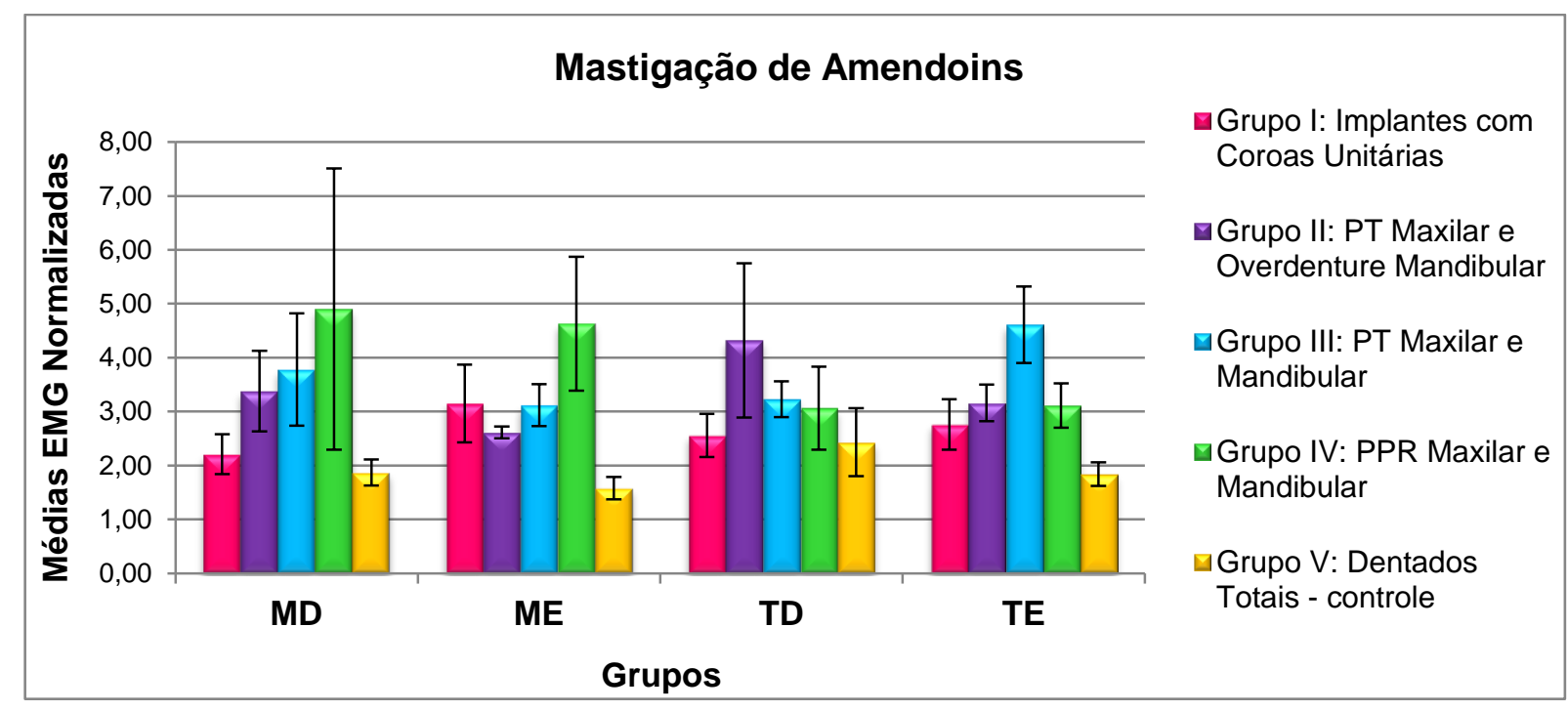

Figura 3: Médias eletromiográficas normalizadas (microvolts/segundo) dos cinco grupos avaliados na condição clínica de Mastigação de Amendoins. 
Tabela 1: Médias eletromiográficas normalizadas (microvolts/segundo) e erro-padrão (ANOVA) dos cinco grupos analisados durante a Condição Clínica de Mastigação de Amendoins.

\begin{tabular}{|c|c|c|c|}
\hline Grupos e músculos & $\mathbf{N}$ & Médias e Erro Padrão & Significância \\
\hline Masseter Direito & & & 0,49 \\
\hline Implantes com Coroas Unitárias & 10 & $2,21 \pm 0,37$ & \\
\hline PT Maxilar e Overdenture Mandibular & 10 & $3,38 \pm 0,75$ & \\
\hline PT Maxilar e Mandibular & 10 & $3,78 \pm 1,04$ & \\
\hline PPR Maxilar e Mandibular & 10 & $4,90 \pm 2,61$ & \\
\hline Dentados Totais (controle) & 10 & $1,87 \pm 0,24$ & \\
\hline Masseter Esquerdo & & & 0,04 \\
\hline Implantes com Coroas Unitárias & 10 & $3,15 \pm 0,72$ & \\
\hline PT Maxilar e Overdenture Mandibular & 10 & $2,61 \pm 0,11$ & \\
\hline PT Maxilar e Mandibular & 10 & $3,12 \pm 0,39$ & \\
\hline PPR Maxilar e Mandibular & 10 & $4,63 \pm 1,24$ & \\
\hline Dentados Totais (controle) & 10 & $1,58 \pm 0,21$ & \\
\hline Temporal Direito & & & 0,50 \\
\hline Implantes com Coroas Unitárias & 10 & $2,56 \pm 0,40$ & \\
\hline PT Maxilar e Overdenture Mandibular & 10 & $4,32 \pm 1,43$ & \\
\hline PT Maxilar e Mandibular & 10 & $3,23 \pm 0,33$ & \\
\hline PPR Maxilar e Mandibular & 10 & $3,06 \pm 0,77$ & \\
\hline Dentados Totais (controle) & 10 & $2,43 \pm 0,63$ & \\
\hline Temporal Esquerdo & & & 0,00 \\
\hline Implantes com Coroas Unitárias & 10 & $2,76 \pm 0,47$ & \\
\hline PT Maxilar e Overdenture Mandibular & 10 & $3,16 \pm 0,34$ & \\
\hline PT Maxilar e Mandibular & 10 & $4,61 \pm 0,71$ & \\
\hline PPR Maxilar e Mandibular & 10 & $3,11 \pm 0,41$ & \\
\hline Dentados Totais (controle) & 10 & $1,84 \pm 0,22$ & \\
\hline
\end{tabular}

* Significância estatística para $p \leq 0,05$. 


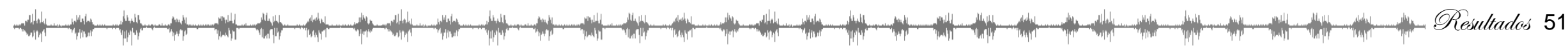

Tabela 2: Teste complementar de Duncan na comparação entre os grupos: Condição Clínica de Mastigação de Amendoins.

\begin{tabular}{|c|c|c|c|c|c|c|c|}
\hline \multirow[t]{2}{*}{ Grupos } & \multirow[t]{2}{*}{$\mathrm{N}$} & \multirow{2}{*}{$\begin{array}{c}\text { Masseter Direito } \\
p \leq 0,05 \\
1\end{array}$} & \multicolumn{2}{|c|}{$\begin{array}{l}\text { Masseter Esquerdo } \\
\qquad \leq 0,05\end{array}$} & \multirow{2}{*}{$\begin{array}{c}\text { Temporal Direito } \\
p \leq 0,05\end{array}$} & \multicolumn{2}{|c|}{$\begin{array}{c}\text { Temporal Esquerdo } \\
\boldsymbol{p} \leq 0,05\end{array}$} \\
\hline & & & 1 & 2 & & 1 & 2 \\
\hline $\begin{array}{l}\text { Grupo I: Implantes com } \\
\text { Coroas Unitárias }\end{array}$ & 10 & 2,21 & 3,15 & 3,15 & 2,56 & 2,76 & \\
\hline $\begin{array}{l}\text { Grupo II: PT Maxilar e } \\
\text { Overdenture Mandibular }\end{array}$ & 10 & 3,38 & 2,61 & 2,61 & 4,32 & 3,16 & \\
\hline $\begin{array}{l}\text { Grupo III: PT Maxilar e } \\
\text { Mandibular }\end{array}$ & 10 & 3,78 & 3,12 & 3,12 & 3,23 & & 4,61 \\
\hline $\begin{array}{l}\text { Grupo IV: PPR Maxilar e } \\
\text { Mandibular }\end{array}$ & 10 & 4,90 & & 4,63 & 3,06 & 3,11 & \\
\hline Grupo V: Dentados Totais & 10 & 1,87 & 1,58 & & 2,43 & 1,84 & \\
\hline
\end{tabular}

* Números diferentes indicam diferença estatística $(p \leq 0,05)$ na comparação da coluna. 


\section{2- Resultados na Condição Clínica de Mastigação de UVAs Passas sem SEMENTES}

Na condição clínica habitual de mastigação de uvas passas sem sementes verificouse que ocorreu diferença estatisticamente significativa $(p<0,05)$ somente para o músculo temporal esquerdo. As médias eletromiográficas normalizadas revelaram que o grupo IV, indivíduos portadores de Prótese Parcial Removível Maxilar e Mandibular apresentaram valores maiores para os músculos masseter direito e esquerdo. Porém, o grupo II, indivíduos portadores de Prótese Total Maxilar e Overdenture Mandibular obtiveram maiores médias eletromiográficas normalizadas para o músculo temporal direito e o grupo III, indivíduos portadores de Prótese Total Maxilar e Mandibular apresentaram valores maiores para o músculo temporal esquerdo, sendo a maior média para todos os grupos avaliados. O grupo V (Dentados Totais) apresentou os menores valores de médias eletromiográficas normalizadas para todos os músculos estudados (Figura 4 e Tabela 3). O teste complementar de Duncan pode ser verificado na Tabela 4.

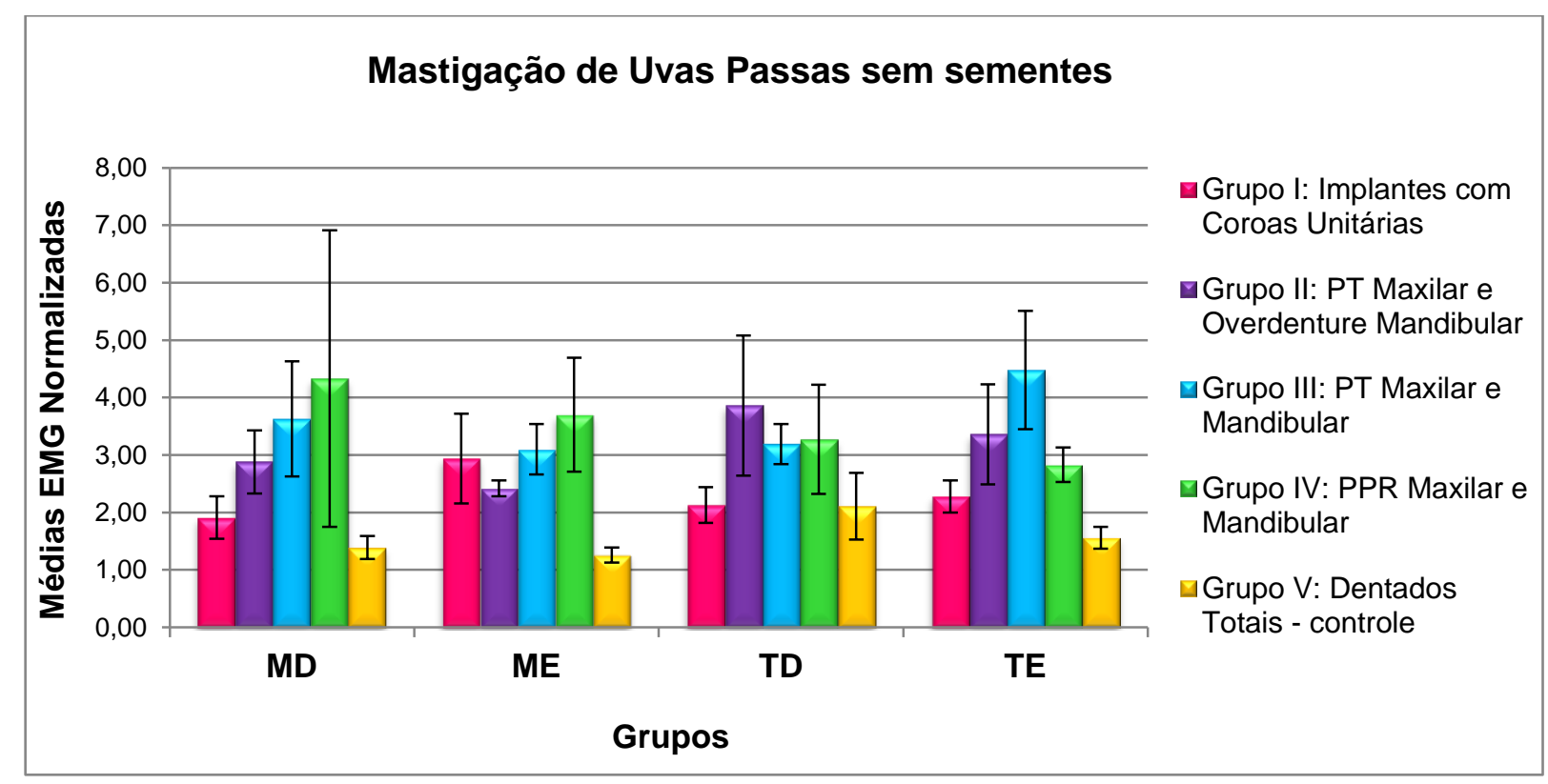

Figura 4: Médias eletromiográficas normalizadas (microvolts/segundo) dos músculos Masseter Direito, Masseter Esquerdo, Temporal Direito e Temporal Esquerdo: Condição Clínica de Mastigação de Uvas Passas. 
Tabela 3: Médias eletromiográficas normalizadas (microvolts/segundo) e erro-padrão (ANOVA) dos cinco grupos analisados durante a Condição Clínica de Mastigação de Uvas Passas sem sementes.

\begin{tabular}{|c|c|c|c|}
\hline Grupos e músculos & $\mathbf{N}$ & Médias e Erro Padrão & Significância \\
\hline Masseter Direito & & & 0,47 \\
\hline Implantes com Coroas Unitárias & 10 & $1,91 \pm 0,37$ & \\
\hline PT Maxilar e Overdenture Mandibular & 10 & $2,88 \pm 0,55$ & \\
\hline PT Maxilar e Mandibular & 10 & $3,63 \pm 1,00$ & \\
\hline PPR Maxilar e Mandibular & 10 & $4,33 \pm 2,58$ & \\
\hline Dentados Totais (controle) & 10 & $1,39 \pm 0,20$ & \\
\hline Masseter Esquerdo & & & 0,07 \\
\hline Implantes com Coroas Unitárias & 10 & $2,94 \pm 0,78$ & \\
\hline PT Maxilar e Overdenture Mandibular & 10 & $2,42 \pm 0,14$ & \\
\hline PT Maxilar e Mandibular & 10 & $3,10 \pm 0,44$ & \\
\hline PPR Maxilar e Mandibular & 10 & $3,70 \pm 0,99$ & \\
\hline Dentados Totais (controle) & 10 & $1,26 \pm 0,13$ & \\
\hline Temporal Direito & & & 0,42 \\
\hline Implantes com Coroas Unitárias & 10 & $2,13 \pm 0,31$ & \\
\hline PT Maxilar e Overdenture Mandibular & 10 & $3,86 \pm 1,22$ & \\
\hline PT Maxilar e Mandibular & 10 & $3,19 \pm 0,35$ & \\
\hline PPR Maxilar e Mandibular & 10 & $3,27 \pm 0,95$ & \\
\hline Dentados Totais (controle) & 10 & $2,11 \pm 0,58$ & \\
\hline Temporal Esquerdo & & & 0,02 \\
\hline Implantes com Coroas Unitárias & 10 & $2,28 \pm 0,28$ & \\
\hline PT Maxilar e Overdenture Mandibular & 10 & $3,36 \pm 0,87$ & \\
\hline PT Maxilar e Mandibular & 10 & $4,48 \pm 1,03$ & \\
\hline PPR Maxilar e Mandibular & 10 & $2,83 \pm 0,30$ & \\
\hline Dentados Totais (controle) & 10 & $1,56 \pm 0,19$ & \\
\hline
\end{tabular}

* Significância estatística para p $\leq 0,05$. 
Tabela 4: Teste complementar de Duncan na comparação entre grupos: Condição Clínica de Mastigação de Uvas Passas sem sementes

\begin{tabular}{|c|c|c|c|c|c|c|c|}
\hline \multirow{2}{*}{ Grupos } & \multirow[t]{2}{*}{$\mathrm{N}$} & \multirow{2}{*}{$\begin{array}{c}\text { Masseter Direito } \\
p \leq 0,05 \\
1\end{array}$} & \multicolumn{2}{|c|}{$\begin{array}{c}\text { Masseter Esquerdo } \\
p \leq 0,05\end{array}$} & \multirow{2}{*}{$\begin{array}{c}\text { Temporal Direito } \\
p \leq 0,05 \\
1\end{array}$} & \multicolumn{2}{|c|}{$\begin{array}{c}\text { Temporal Esquerdo } \\
p \leq 0,05\end{array}$} \\
\hline & & & 1 & 2 & & 1 & 2 \\
\hline $\begin{array}{l}\text { Grupo I: Implantes com } \\
\text { Coroas Unitárias }\end{array}$ & 10 & 1,91 & 2,94 & 2,94 & 2,13 & 2,28 & \\
\hline $\begin{array}{l}\text { Grupo II: PT Maxilar e } \\
\text { Overdenture Mandibular }\end{array}$ & 10 & 2,88 & 2,42 & 2,42 & 3,86 & 3,36 & 3,36 \\
\hline $\begin{array}{l}\text { Grupo III: PT Maxilar e } \\
\text { Mandibular }\end{array}$ & 10 & 3,63 & 3,10 & 3,10 & 3,19 & & 4,48 \\
\hline $\begin{array}{l}\text { Grupo IV: PPR Maxilar e } \\
\text { Mandibular }\end{array}$ & 10 & 4,33 & & 3,70 & 3,27 & 2,83 & 2,83 \\
\hline Grupo V: Dentados Totais & 10 & 1,39 & 1,26 & & 2,11 & 1,56 & \\
\hline
\end{tabular}

* Números diferentes indicam diferença estatística $(p \leq 0,05)$ na comparação da coluna. 


\section{3- Resultados na Condição Clínica de Mastigação de Parafilme}

Na condição clínica de mastigação não-habitual de Parafilme, a análise dos dados revelou que ocorreu diferença estatisticamente significativa $(p<0,05)$ para o músculo temporal esquerdo. As médias eletromiográficas normalizadas revelaram que o grupo III, indivíduos portadores de Prótese Total Maxilar e Mandibular apresentaram maiores valores que os demais grupos para todos os músculos analisados, diferentemente do grupo $\mathrm{V}$, Dentados Totais, que apresentaram as menores médias normalizadas eletromiográficas em todos os músculos estudados na condição clínica de mastigação de Parafilme (Figura 5 e Tabela 5). O teste complementar de Duncan pode ser verificado na Tabela 6.

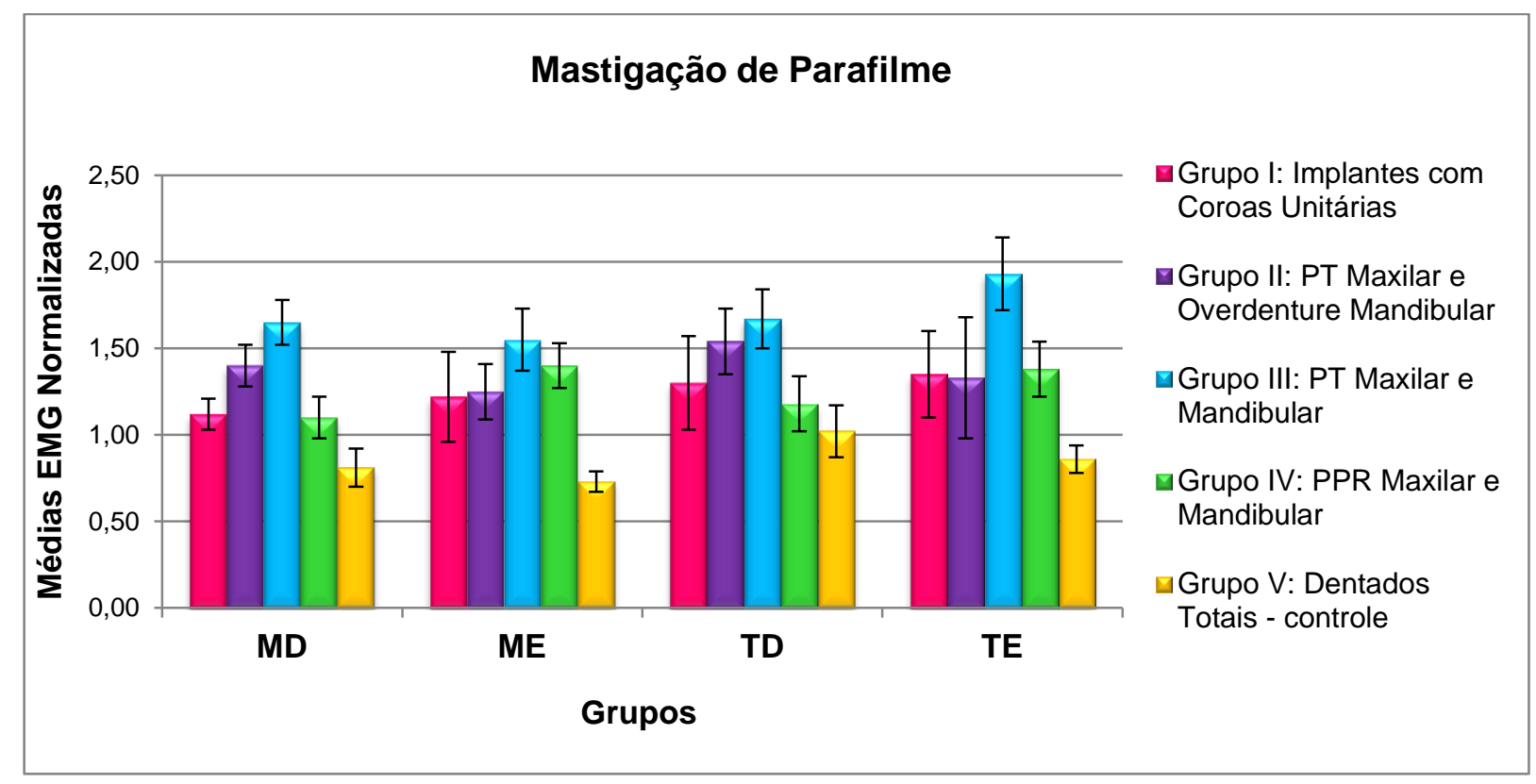

Figura 5: Médias eletromiográficas normalizadas (microvolts/segundo) dos músculos Masseter Direito, Masseter Esquerdo, Temporal Direito e Temporal Esquerdo: Condição Clínica de Mastigação Não Habitual de Parafilme. 
Tabela 5: Médias eletromiográficas normalizadas (microvolts/segundo) e erro-padrão (ANOVA) dos cinco grupos analisados durante a Condição Clínica de Mastigação de Parafilme.

\begin{tabular}{|c|c|c|c|}
\hline Grupos e músculos & $\mathbf{N}$ & Médias e Erro Padrão & Significância \\
\hline Masseter Direito & & & 0,08 \\
\hline Implantes com Coroas Unitárias & 10 & $1,12 \pm 0,09$ & \\
\hline PT Maxilar e Overdenture Mandibular & 10 & $1,40 \pm 0,26$ & \\
\hline PT Maxilar e Mandibular & 10 & $1,65 \pm 0,27$ & \\
\hline PPR Maxilar e Mandibular & 10 & $1,10 \pm 0,25$ & \\
\hline Dentados Totais (controle) & 10 & $0,81 \pm 0,11$ & \\
\hline Masseter Esquerdo & & & 0,08 \\
\hline Implantes com Coroas Unitárias & 10 & $1,22 \pm 0,12$ & \\
\hline PT Maxilar e Overdenture Mandibular & 10 & $1,25 \pm 0,16$ & \\
\hline PT Maxilar e Mandibular & 10 & $1,55 \pm 0,19$ & \\
\hline PPR Maxilar e Mandibular & 10 & $1,40 \pm 0,35$ & \\
\hline Dentados Totais (controle) & 10 & $0,73 \pm 0,06$ & \\
\hline Temporal Direito & & & 0,07 \\
\hline Implantes com Coroas Unitárias & 10 & $1,30 \pm 0,13$ & \\
\hline PT Maxilar e Overdenture Mandibular & 10 & $1,54 \pm 0,18$ & \\
\hline PT Maxilar e Mandibular & 10 & $1,67 \pm 0,17$ & \\
\hline PPR Maxilar e Mandibular & 10 & $1,18 \pm 0,21$ & \\
\hline Dentados Totais (controle) & 10 & $1,02 \pm 0,15$ & \\
\hline Temporal Esquerdo & & & 0,00 \\
\hline Implantes com Coroas Unitárias & 10 & $1,35 \pm 0,12$ & \\
\hline PT Maxilar e Overdenture Mandibular & 10 & $1,33 \pm 0,13$ & \\
\hline PT Maxilar e Mandibular & 10 & $1,93 \pm 0,16$ & \\
\hline PPR Maxilar e Mandibular & 10 & $1,38 \pm 0,16$ & \\
\hline Dentados Totais (controle) & 10 & $0,86 \pm 0,08$ & \\
\hline
\end{tabular}

* Significância estatística para p $\leq 0,05$. 


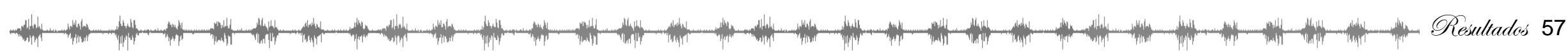

Tabela 6: Teste complementar de Duncan na comparação entre grupos: Condição Clínica de Mastigação Não-Habitual de Parafilme.

\begin{tabular}{|c|c|c|c|c|c|c|c|c|c|c|}
\hline \multirow[t]{2}{*}{ Grupos } & \multirow[t]{2}{*}{$\mathrm{N}$} & \multicolumn{2}{|c|}{$\begin{array}{c}\text { Masseter Direito } \\
p \leq 0,05 \\
\end{array}$} & \multicolumn{2}{|c|}{$\begin{array}{c}\text { Masseter Esquerdo } \\
p \leq 0,05\end{array}$} & \multicolumn{2}{|c|}{$\begin{array}{c}\text { Temporal Direito } \\
\boldsymbol{p} \leq \mathbf{0 , 0 5} \\
\end{array}$} & \multicolumn{3}{|c|}{$\begin{array}{c}\text { Temporal Esquerdo } \\
\boldsymbol{p} \leq \mathbf{0 , 0 5}\end{array}$} \\
\hline & & 1 & 2 & 1 & 2 & 1 & 2 & 1 & 2 & 3 \\
\hline $\begin{array}{l}\text { Grupo I: Implantes com } \\
\text { Coroas Unitárias }\end{array}$ & 10 & 1,12 & 1,12 & 1,22 & 1,22 & 1,30 & 1,30 & & 1,35 & \\
\hline $\begin{array}{l}\text { Grupo II: PT Maxilar e } \\
\text { Overdenture Mandibular }\end{array}$ & 10 & 1,40 & 1,40 & 1,25 & 1,25 & 1,54 & 1,54 & & 1,33 & \\
\hline $\begin{array}{l}\text { Grupo III: PT Maxilar e } \\
\text { Mandibular }\end{array}$ & 10 & & 1,65 & & 1,55 & & 1,67 & & & 1,93 \\
\hline $\begin{array}{l}\text { Grupo IV: PPR Maxilar e } \\
\text { Mandibular }\end{array}$ & 10 & 1,10 & 1,10 & & 1,40 & 1,18 & 1,18 & & 1,38 & \\
\hline Grupo V: Dentados Totais & 10 & 0,81 & & 0,73 & 1,55 & 1,02 & & 0,86 & & \\
\hline
\end{tabular}

${ }^{*}$ Números diferentes indicam diferença estatística $(p \leq 0,05)$ na comparação da coluna. 


\section{6. $\mathscr{D P}_{\text {inestrixic }}$}




\section{Discussão}

O sistema estomatognático é constituído por um conjunto de estruturas que atuam de forma coordenada em funções digestórias, comunicativas, respiratórias, defensivas e/ou agressivas, compreendendo a sucção, a deglutição, a mastigação, a fonoarticulação e a respiração (DOUGLAS, 1998). Dentre elas, a mastigação é uma das atividades mais importantes do sistema estomatognático, considerada um mecanismo motor neurofisiológico complexo e sofisticado (ORCHARDSON; CADDEN, 1998), o passo inicial dentro do processo digestório, que pode ser subdividida em uma parte voluntária, quando há a decisão de mastigar os alimentos e uma segunda parte, involuntária, que envolve a deglutição propriamente dita, dependente de um gerador central neural que programa a interação de receptores e nervos (THEXTON et al.,1982; MOHL et al. 1988; KARKAZI; KOSSIONI, 1997).

$\mathrm{Na}$ mastigação, observa-se uma integração da atividade neuromuscular, com a coordenação sincrônica dos músculos da mastigação e os auxiliares, responsáveis pelos movimentos de lateralidade, protrusão, abertura e fechamento da boca (MOYERS, 1991). Para Planas (1987), Molina (1989), Simões (1998) e McNeill (2000) a manutenção da morfologia dos arcos dentais e a estabilidade da oclusão estão diretamente relacionadas aos hábitos mastigatórios e a performance dos ciclos mastigatórios, que tem por função fragmentar os alimentos. Esta fragmentação também é influenciada pela força de mordida e o número de pares de dentes em oclusão (FONTIJN-TEKAMP et al., 2004).

Segundo Van der Bilt et al., 1993, existem divergências quanto ao número de ciclos mastigatórios necessários para fragmentar os alimentos, mas indivíduos com uma dentição inadequada e/ou uma reabilitação bucal mal executada determina que usem mais ciclos 
mastigatórios para preparar o alimento para a deglutição do que indivíduos com dentição natural, podendo ainda apresentarem reduzida performance mastigatória, o que os levaria a deglutir partículas maiores de alimentos (Van der Bilt et al., 1993; Fontijn-Tekamp et al., 2004), resultados concordes com este trabalho onde verificou-se que os indivíduos dentados realizaram as mastigações habitual e não-habitual com menor ativação eletromiográfica para todos os músculos, dados estes representados pelos menores valores da área dos ciclos mastigatórios (integral da envoltória).

Com a perda progressiva dos elementos dentais muitas transformações são observadas no sistema mastigatório, como perda da função, de dimensão vertical, estética e fonética. Os resultados dos procedimentos utilizados na reabilitação protética da cavidade da boca incidem na atividade da musculatura mastigatória, pois o sistema estomatognático é formado por um conjunto de estruturas que agem harmoniosamente durante a função da mastigação (SIMÕES, 1979; HARPER et al., 1997; KARKAZIS; KOSSIONI, 1997).

A partir da década de 1980, os indivíduos edêntulos obtiveram diversas opções com o advento dos implantes dentais osseointegrados e o uso dos mesmos em próteses implanto-suportadas, que permitem um aumento da fixação das próteses totais ao rebordo alveolar, principalmente as próteses inferiores, que apresentam grande dificuldade de estabilidade e retenção. O uso de implantes tem sido relacionado a uma melhora da função oral, principalmente com relação à mastigação, com relatos de aumento de satisfação, habilidade e eficiência mastigatória (PERA et al., 1998; AWAD et al., 2003)

Sabe-se que reabilitações bucais, mesmo quando bem executadas, podem não devolver aos indivíduos todos os parâmetros funcionais comparados aos indivíduos dentados, principalmente com relação à eficiência e a qualidade funcional mastigatória (PERA et al., 1998). Esta pesquisa teve o objetivo de analisar indivíduos com diferentes reabilitações bucais na mastigação habitual de alimentos macios e duros e na mastigação bilateral, não-habitual e contínua, padronizada, de um material inerte, de forma que fosse possível estabelecer comparações entre os diferentes grupos reabilitados com indivíduos dentados totais nas mastigações, pois os grupos, mesmo estando todos reabilitados de 


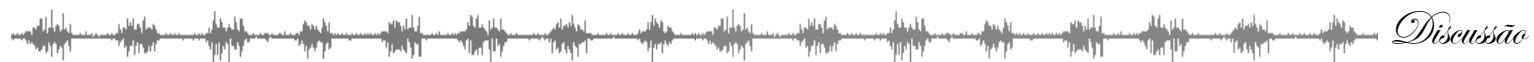

forma satisfatória, funcionalmente poderiam apresentar padrões de ativação muscular diferentes, o que foi efetivamente observado.

Os resultados da mastigação habitual de amendoins e de uvas passas sem sementes evidenciaram que os indivíduos reabilitados com próteses totais, overdenture e próteses removíveis apresentaram uma maior ativação eletromiográfica dos ciclos mastigatórios quando comparados com os indivíduos com implantes e dentados, seja para o músculo masseter ou temporal, dados estes semelhantes aos da análise da mastigação com Parafilme, resultados semelhantes aos obtidos nos trabalhos de Van der Bilt et al., 1993; Fontijn-Tekamp et al., 2004 e Bersani, 2009.

Julien et al., 1996, verificaram que manter o maior número de dentes naturais é a melhor garantia de uma boa eficiência mastigatória, resultados concordes com os desta pesquisa, onde os indivíduos dentados apresentaram menor ativação dos ciclos mastigatórios para mastigarem alimentos duros ou macios, assim como na mastigação controlada com Parafilme.

A estabilização da oclusão gerada pelo uso de próteses pode evidenciar considerável modificação da atividade muscular e dos movimentos mandibulares (SANTOS et al., 2008). O fato dos indivíduos portadores de próteses totais e overdenture apresentarem atividade eletromiográfica maior durante a mastigação poderia ser indício de alteração funcional do sistema estomatognático, apesar dos indivíduos terem sido avaliados clinicamente e, nenhum deles ter qualquer sinal ou sintoma de disfunção temporomandibular. Cumpre ressaltar que todas as reabilitações bucais foram avaliadas e notou-se a presença de rigor nos critérios básicos para a confecção de próteses satisfatórias.

Segundo Paesani et al., 1994, a disfunção muscular promove a diminuição da atividade eletromiográfica quando comparada com a atividade de indivíduos sadios, e não causa hiperatividade, dados estes discordes dos verificados neste trabalho. Deve-se ressaltar que nesta pesquisa foi avaliado a eficiência mastigatória por meio da área dos ciclos mastigatórios e os valores eletromiográficos maiores durante a mastigação 
representam que os indivíduos reabilitados orais, independente dos procedimentos executados, inclusive implantes, para executarem a mastigação, no mesmo prazo de tempo (dez segundos) despenderam maior quantidade de energia que os indivíduos dentados. Este fato pode ser consequência da perda dos dentes, dos ligamentos periodontais e da propriocepção (SANTOS et al., 2008), o que poderia ter gerado uma menor capacidade dos indivíduos reabilitados perceberem o controle das forças exercidas durante a mastigação.

A ativação eletromiográfica reduzida dos músculos temporais quando comparada com os músculos masseteres é a situação esperada para indivíduos com bom funcionamento do sistema estomatognático durante funções que requerem força muscular, e dificilmente esta situação é encontrada em indivíduos portadores de próteses totais (SANTOS et al., 2008). Neste trabalho, na maioria das vezes, os resultados evidenciaram uma maior ativação dos músculos temporais durante a mastigação em todos os grupos. $\mathrm{Na}$ mastigação do alimento macio (uvas passas sem sementes) e Parafilme, isso poderia ser esperado, pois os músculos temporais são funcionalmente mais ativos em movimentos rápidos da mandíbula (SIÉSSERE et al., 2009), mas com relação ao amendoim, onde exigese força de mastigação, era esperado que os músculos masseteres estivessem mais ativos (SIÉSSERE et al., 2009), nesta pesquisa, este resultado não foi verificado nem mesmo para o grupo dentado.

Em situações clínicas posturais da mandíbula, a maior ativação dos músculos temporais pode acontecer devido à sensibilidade maior do mesmo às mudanças de relacionamento intermaxilar e de instabilidade das reabilitações bucais utilizadas (TALLGREN et al., 1995, SANTOS et al., 2008). Como este músculo é mais sensitivo que o músculo masseter, ele pode se manter mais ativado em indivíduos reabilitados oralmente e menos ativado em indivíduos dentados, fato este não observado nesta pesquisa, onde de forma geral, os músculos temporais foram mais ativos durante as mastigações.

Chen et al. (2002) analisaram a atividade mastigatória de indivíduos portadores de overdentures e indivíduos com próteses totais e verificaram atividade preponderante do músculo temporal em relação à atividade do músculo masseter, desenvolvida durante a 




mastigação. A hiperatividade eletromiográfica do músculo temporal quando comparada com a atividade do músculo masseter também foi verificada por Slagter et al. (1993) quando indivíduos portadores de próteses totais realizaram movimentos mastigatórios, resultados estes concordes com os deste trabalho.

Mahmood et al. (1992) determinaram à eficiência mastigatória antes e após indivíduos serem reabilitados com próteses totais imediatas, comparando-os com indivíduos dentados e com indivíduos portadores de próteses totais. Evidenciaram que os indivíduos dentados foram significantemente mais eficientes para mastigar o alimento teste do que os indivíduos portadores de próteses totais ou com as próteses imediatas, resultados semelhantes aos desta pesquisa.

Fontijn-Tekamp et al. (2001) analisaram indivíduos reabilitados com próteses totais e indivíduos portadores de overdentures sobre implantes e observaram que grande parte dos indivíduos portadores de próteses totais (88\%) relataram sintomatologia dolorosa na mandíbula durante a mastigação habitual e somente $13 \%$ ou menos dos indivíduos portadores de overdentures sobre implantes relataram dor no rebordo mandibular. Em compensação, os indivíduos portadores de overdentures inferiores relataram com maior freqüência sintomas dolorosos no rebordo superior reabilitado com próteses totais quando comparados com os indivíduos portadores de próteses totais maxilar e mandibular. Concluíram que o uso de implantes permitiu a diminuição dos sintomas dolorosos na região mandibular, o que poderia explicar a melhora no desempenho funcional dos indivíduos reabilitados com implantes verificados neste trabalho. As funções táteis promovidas por implantes são diferentes das promovidas por dentição natural (FERRARIO et al., 2004), e também por estes motivos os indivíduos dentados apresentaram melhor desempenho durante movimentos mastigatórios.

Estudos afirmam que os portadores de próteses totais necessitam de maior atividade muscular para macerar um alimento (EERIKÄINEN; KÖNÖNEN, 1987; FONTIIN-TEKAMP et al., 2000; GOIATO et al., 2010) quando comparados com indivíduos dentados totais. Isto corrobora os resultados obtidos neste estudo, onde foi possível observar a grande atividade 
desenvolvida durante a mastigação habitual e não habitual em indivíduos portadores de próteses totais.

Dessa forma, a eletromiografia, sem dúvida, constitui uma metodologia que tem contribuído para a compreensão do desempenho da musculatura mastigatória nas diversas condições clínicas como a deglutição, oclusão, mastigação e fala (VITTI et al., 1975; LOWE; JOHNSTON, 1979; TOSELLO et al., 1998; REGALO et al., 2003; SANTOS, 2005; GALO et al., 2006; ZUCOLOTTO et al., 2007; SIÉSSERE et al., 2009).

Neste estudo, a análise eletromiográfica normalizada foi fundamental para avaliar o desempenho da atividade dos músculos masseteres e temporais nas diferentes condições clínicas. A normalização do sinal eletromiográfico reduz as imperfeições entre os diferentes registros de um mesmo sujeito, ou de sujeitos diferentes de forma a tornar a interpretação dos dados reprodutível e o uso da contração isométrica voluntária máxima é a forma mais utilizada na literatura (SODEBERG; COOK, 1984; WINTER, 1984; BAO et al., 1995; MATHIASSEN et al., 1995; REGALO et al., 2006b; REGALO et al., 2008).

Assim, os dados de mastigação deste trabalho foram normalizados seguindo a recomendação do SENIAM (European Recommendations for Surface Electromyography) para grupos comparativos entre indivíduos e diferentes músculos, pela grande variabilidade da amplitude do sinal eletromiográfico em registros eletromiográficos, relacionada à instrumentação e a fatores individuais, tais como a composição das fibras, gordura subcutânea, geometria muscular e impedância dos tecidos. Nesta pesquisa foi utilizado como valor de referência para a normalização dos dados eletromiográficos os valores da integral da envoltória do apertamento dental máximo voluntário por quatro segundos, correspondente ao valor da contração isométrica voluntária máxima, tempo considerado suficiente e possível de execução pelo indivíduo (REGALO et al., 2008).

Neste estudo ficou evidente que o tipo de reabilitação bucal realizado apresentam relação direta com a eficiência dos ciclos mastigatórios, sendo maior em indivíduos reabilitados com próteses dentossuportadas e implantossuportadas se comparados com indivíduos portadores de próteses totais convencionais e/ou próteses parciais removíveis. 


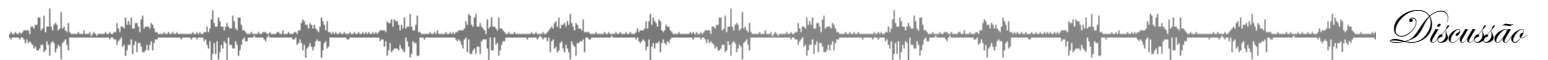

Assim, o uso de próteses implantossuportadas leva à melhor função mastigatória, caracterizada por redução do tempo do ciclo mastigatório, embora a coordenação neuromuscular seja menor em comparação com indivíduos com dentes naturais, resultados semelhantes aos verificados por Berretin-Felix et al., em 2008.

Berretin-Felix et al. (2009) avaliaram a necessidade de reabilitações com implantes para indivíduos com perdas dentais visando obter resultados que melhorassem a função mastigatória, tendo em vista que, na maior parte das vezes, a dificuldade na mastigação estava relacionada à instabilidade das próteses maxilares e mandibulares. Verificaram que as reabilitações bucais implantossuportadas (overdentures) proporcionam performance mastigatória similar àquela observada em indivíduos com dentição natural, além de aumentar a força de mordida máxima.

A análise eletromiográfica dos ciclos mastigatórios torna-se cada vez mais útil ao profissional da área da saúde, principalmente aos cirurgiões dentistas, por contribuir para o conhecimento do desempenho funcional nos movimentos dos reflexos reguladores e nas mudanças do padrão muscular do sistema estomatognático como um todo.

Os efeitos dos diferentes tipos de reabilitações protéticas na atuação da musculatura mastigatória não estão completamente estabelecidos. Salienta-se a necessidade da realização de pesquisas futuras que enfoquem padrões morfológicos faciais diferentes, comparação entre idade, gênero, estudos longitudinais para o conhecimento e controle da atividade muscular e função mastigatória. 


\section{Comenterices}




\section{Conclusões}

Os dados deste estudo forneceram fundamento para concluir que:

1. A eficiência mastigatória foi influenciada pelo tipo de reabilitação protética bucal.

2. Na mastigação habitual de amendoins e uvas passas sem sementes, o grupo dentado total apresentou maior eficiência mastigatória;

3. Na mastigação não habitual de Parafilme, o grupo dentado total apresentou maior eficiência mastigatória;

4. O grupo portador de implantes com coroas unitárias apresentou os resultados de eficiência de ciclos mastigatórios mais semelhantes ao grupo dentado total em todas as condições clínicas estudadas;

5. O grupo portador de próteses totais maxilares e mandibulares apresentou o pior desempenho de eficiência de ciclos mastigatórios na condição clínica de mastigação não-habitual de Parafilme. 
OReferências@OBibliográficas 


\section{ReFERÊnCias Bibliográficas}

1. AHLGREN, J. Mechanisms of mastication. Acta Odontol Scand, v.24 (Suppl. 44), p.1-10, 1976.

2. AKAGAWA, Y.; OKANE, H.; KONDO, N.; TSUGA, K.; TSURU, H. Comparative Evaluation of Chewing Function with Removable Partial Dentures and Fixed Prostheses Supported by the Single-Crystal Sapphire Implant in the Kennedy Class II Partially Edentulous Mandible JOMI on CD-ROM, Mar (205-210) 1989.

3. ANDRADE, A.S.; GAVIÃO, M.B.D.; DE ROSSI, M.; GAMEIRO, G.H. Electromyographic Activity and Thickness of Masticatory Muscles in Children With Unilateral Posterior Crossbite. Clin Anat, v.22, n.2, p.200-206, 2009.

4. AP BIASOTTO-GONZALEZ, D.; BERZIN, F.; DA COSTA, J.M.; DE GONZALEZ, T.O. Electromyographic study of stomatognathic system muscles during chewing of different materials. Electromyogr Clin Neurophysiol, v.50, n.2, p.121-127, 2010.

5. AWAD, M. A.; LUND, J.P.; DUFRESNE, E.; FEINE, J.S. Comparing the efficacy of mandibular implant-retained overdentures among middle-aged edentulous patients: satisfaction and functional assessment. Int J Prosth, v.16, n.2, p.117-122, 2003.

6. BAO, S.; MATHIASSEN, S.E.; WINKEL, J. Normalization Upper Trapezius EMG Amplitude: Comparison of Different Procedures. J Electromyogr Kinesiol, v.5, n.4, p.251-257, 1995.

7. BATES, J.F.; STAFFORD, G.D; HARRISON, A. Masticatory function - a review of the literature. III. Masticatory performance and efficiency. J Oral Rehabil, v.3, n.1, p.5767, 1976.

8. BAZZOTTI, L. Electromyography tension and frequency spectrum analysis of some masticatory muscles at rest, isotonic and isometric contractions. Electromyogr Clin Neurophysiol, v.39, n.7, p.421-434, 1999.

9. BEECHER, R.M.; CORRUCCINI, R.S. Effects of dietary concistency on cranifacial and occusal development.in the rat. Angle Orthod Appleton, v.51, n.1, p.61-69, 1981.

10. BERRETIN-FELIX, G.; MACHADO, W.M.; GENARO, K.F.; NARY FILHO, H. Effects of mandibular fixed implant-supported prostheses on masticatory and swallowing functions in completely edentulous elderly individuals. Int $\mathbf{J}$ Oral Maxillofac Implants, v.24, n.1, p.110-117, 2009.

11. BERRETIN-FELIX, G.; NARY FILHO, H.; PADOVANI, C.R.; TRINDADE JUNIOR, A.S.; MACHADO, W.M. Electromyographic evaluation of mastication and swallowing

`De acordo com a Associação Brasileira de Normas Técnicas. NBR 6023.

Abreviaturas dos periódicos em conformidade com Baseline. 
in elderly individuals with mandibular fixed implantsupported prostheses. J Appl Oral Sci, v.16, n.2, p.116-121, 2008.

12. BERSANI, E. Efeito do uso de próteses fixas sobre implantes tipo protocolo BRANEMARK na atividade eletromiográfica da musculatura da mastigação. [Dissertação de mestrado], Ribeirão Preto: Faculdade de Odontologia de Ribeirão Preto da Universidade de São Paulo; 2009.

13. BEYRON, H. Occlusal relations and mastication in australian aborigines. Acta Odontol Scand, v.22, p.597-678, 1964.

14. BLANKSMA, N.G.; VAN EIJDEN, T.M. Electromyographic heterogeneity in the human temporalis and masseter muscles during static biting, open/close excursions, and chewing. J Dent Res, v.74, n.6, p.1318-1327, 1995.

15. BRANAM, S.R.; MOURINO, A.P. Minimizing otitis media by manipulating the primary dental occlusion: case report. J Clin Pediatr Dent, v.22, n.3, p.203-206, 1998.

16. BRANDT, S.K.; RUGH, J.D. Masticatory patterns in children with posterior crossbite. J Dent Res, v.61, p.301, 1982.

17. BROWN, T. Mandibular movements. Monogr Oral Sci., v.4, p.126-50, 1975.

18. BUZINELLI, R.V.; BERZIN, F. Electromyographic analysis of fatigue in temporalis and masseter muscles during continuous chewing. J Oral Rehabil, v.28, n.12, p.11651167, 2001.

19. CARAPITO, S.M.M. Força de mordida no lado de preferência. [Dissertação de Mestrado] São Paulo: Escola Paulista de Medicina da Universidade Federal de São Paulo; 2004.

20. CARLSSON, G.E. Masticatory efficiency: the effect of age, the lost of teeth and prosthetic rehabilitation. Int Dent J, v.34, n.2, p.93-97, 1984.

21. CASTROFLORIO, T.; BRACCO, P.; FARINA, D. Surface electromyography in the assessment of jaw elevator muscles. J Oral Rehabil, v.35, n.8, p.638-645, 2008.

22. CECÍLIO, F.A.; REGALO, S.C.; PALINKAS, M.; ISSA, J.P.; SIÉSSERE, S.; HALLAK, J.E.; MACHADO-DE-SOUSA, J.P.; SEMPRINI, M. Ageing and surface EMG activity patterns of masticatory muscles. J Oral Rehabil, v.37, n.4, p.248-255, 2010.

23. CHEN, L.; XIE, Q.; FENG, H.; LIN, Y.; LI, J. The masticatory efficiency of mandibular implant-supported overdentures as compared with tooth-supported overdentures and complete dentures. J Oral Implantol, v.28, n.5, p.238-243, 2002.

24. CHRISTENSEN, L.V.; RADUE, J.T. Lateral preference in mastication: a feasibility study. J Oral Rehabil, v.12, n.5, p.421-427, 1985.

25. COOPER, B.C. The role of bioelectronic instrumentation in the documentation and management of temporomandibular disorders. Oral Surg Oral Med Oral Pathol Oral Radiol Endod, v.83, n.1, p.91-100, 1997.

26. CRAM, J.R., KASMAN, G.S., HOLTZ, J. Introduction to Surface Electromyography. Ed. Gaithersburg, Maryland: Aspen Publication, p.257-258, 1998. 
27. DAWSON, P.E. Conceito de Odontologia Integral. In: Dawson, P.E. Avaliação, diagnóstico e tratamento dos problemas oclusais. 2a ed. São Paulo: Artes Médicas; p.1-14, 1993.

28. DE LUCA, C.J. The use of surface electromyography in biomechanics. J Appl Biomech., v.13, n.2, p.135-163, 1997.

29. DOUGLAS, C.R. Patofisiologia oral. São Paulo: Pancast; p.245-271, 1998.

30. EERIKÄINEN, E.; KÖNÖNEN, M. Forces required by complete dentures for penetrating food in simulated function. J Oral Rehabilit, v.14, n.6, p.607-613, 1987.

31. ETTALA-YLITALO, U.M.; LAINE, T. Functional disturbances of the masticatory system in relation to articulatory disorders of speech in a group of 6-8-year-old children. Arch Oral Biol, v.36, n.3, p.189-194, 1991.

32. FALTIN JÚNIOR, K.; FALTIN, R.M.; FALTIN, C.O. Ortopedia facial e ortodontia preventiva na saúde bucal. In: Kriger, L. ABOPREV: Promoção de saúde bucal. $3^{a}$. ed. São Paulo: Artes Médicas. p.327-340, 2003.

33. FELÍCIO, C.M. Fonoaudiologia nas desordens temporomandibulares - uma ação educativa terapêutica, São Paulo: Pancast. 1994.

34. FERRARIO, V.F.; SERRAO, G.; DELLAVIA, C.; CARUSO, E.; SFORZA, C. Relationship between the number of occlusal contacts and masticatory muscle activity in health young adults. Cranio, v.20, n.2, p.91-98, 2002.

35. FERRARIO, V.F.; TARTAGLIA, G.M.; MAGLIONE, M.; SIMION, M.; SFORZA, C. Neuromuscular coordination of masticatory muscles in subjects withtwo types of implant-supported prostheses. Clin Oral Impl Res, v.15, n.2, p.219-225, 2004.

36. FIGUN, M.E.; GARINO, R.R. Anatomia Odontológica Funcional e Aplicada, Panamericana, São Paulo, p.61-67, 1994.

37. FONTIIN-TEKAMP, F.A.; SLAGTER, A.P.; VAN DER BILT, A.; VAN T'HOF, M.A.; WITTER, D.J.; KALK, W.; JANSEN, J.A. Biting and Chewing in Overdentures, Full Dentures, and Natural Dentitions. J Dent Res, v.79, n.7, p.1519-1524, 2000.

38. FONTIIN-TEKAMP, F.A.; VAN DER BILT, A., ABBINK, J.H.; BOSMAN, F. Swallowing threshold and masticatory performance in dentate adults. Physiol Behav, v.83, n.3, p.431-436, 2004.

39. FONTIJN-TEKAMP, F.A.; SLAGER, A.P.; VAN 'T HOF, M.A.; KALK, W.; JANSEN, J.A. Pain and instability during biting with mandibular implant-retined overdentures. Clin Oral Impl Res, v.12, n.1, p.46-51. 2001.

40. GALO, R.; VITTI, M.; SANTOS, C.M.; HALLAK, J.E.; REGALO, S.C. The effect of age on the function of the masticatory system-an electromyographical analysis. Gerodontology, v.23, n.3, p.177-182, 2006.

41. GAVIÃO, M.B.D.; RAYMUNDO, V.G.R.; SOBRINHO, L.C. Masticatory efficiency in children with primary dentition. Ped Dent, v.26, n.3, p.499-505, 2001. 
42. GIBBS, C.H.; WICKWIRE, N.A.; JACOBSON, A.P.; LUNDEEN, H.C.; MAHAN, P.E.; LUPKIEWICZ, S.M. Comparison of typical chewing patterns in normal children and adults. J Am Dent Assoc, v.105, n.1, p.33-42, 1982.

43. GLAROS, A.G.; GLASS, E.G.; BROCKMAN, D Electromyographic data from TMD patients with myofascial pain and from matched control subjects: evidence for statistical, not clinical, significance. J Orofac Pain, v.11, n.2, p.125-129, 1997.

44. GOIATO, M.C.; GARCIA, A.R.; DOS SANTOS, D.M. Electromyographic Activity of the Mandible Muscles at the Beginning and End of Masticatory Cycles in Patients with Complete Dentures. Gerontology, v.54, n.3, p.138-143, 2008.

45. GOIATO, M.C.; GARCIA, A.R.; DOS SANTOS, D.M.; ZUIM, P.R. Analysis of masticatory cycle efficiency in complete denture wearers. J Prosthodont, v.19, n.1, p.10-13, 2010.

46. GOMES, S.G.; CUSTODIO, W.; JUFER, J.S.; DEL BEL, C.A.; GARCIA, R.C. Mastication, EMG activity and occlusal contact area in subjects with different facial types. Cranio, v.28, n.4, p.274-279. 2010.

47. GONZÁLEZ, R.; SIFRE, S.; BENEDITO, J.; NOGUÉS, V. Comparison of electromyographic pattern of sensory experts and untrained subjects during chewing of Mahon cheese. J Dairy Res, v.69, n.1, p.151-161, 2002.

48. HANSON, M.L.; BARRETT, R.H. Fundamentos da miologia orofacial. Rio de Janeiro: Enelivros; 1995.

49. HARPER, R.P.; BRUIN, H.; BURCEA, I. Muscle activity during mandibular movements in normal and mandibular retrognathic subjects. J Oral Maxillofac Surg, v.55, n.3, p.225-233, 1997.

50. HAYASAKI, H.; SAWAMI, T.; SAITOH, I.; IWASE, Y.; NAKATA, S.; NAKATA, M. Length of the occlusal glide during chewing in children with primary dentition. $\mathbf{J}$ Oral Rehabil, v.30, n.11, p.1138-1141, 2003.

51. HENRIKSON, T.; EKBERG, E.C.; NILNER, M. Masticatory efficiency and ability in relation to occlusion and mandibular dysfunction in girls. Int $\mathbf{J}$ Prosthodont, v.11, n.2, p.125-132, 1998.

52. HERMENS, H.J.; FRERIKS, B.; MERLETTI, R. European recommendations for surface electromyography - results of the SENIAM project. Deliverable, v.8, p.1358, 1999.

53. HOOGMARTENS, M.J.; CAUBERGH, M.A. Chewing side preference during the first chewing cycle as a new type of lateral preference in man. Electromyogr Clin Neurophysiol, v.27, n.1, p.3-6, 1987.

54. JANKELSON, R.R. Neuromuscular dental diagnosis and treatment. St. Louis: Ishiyaku EuroAmerica Inc, 1990.

55. JULIEN, K.C.; BUSCHANG, P.H.; THROCKMORTON, G.S.; DECHOW, P.C. Normal mastigatory performance in young adults and children. Arch Oral Biol, v.41, n.1, p.69-75, 1996. 
56. KARKAZIS, H.C.; EMG activity of the masseter muscle in implant supported overdenture wearers during chewing of hard and soft food. J Oral Rehabil, v.29, n.10, p.986-991, 2002.

57. KARKAZIS, H.C.; KOSSIONI, A.E. Re-examination of the surface EMG activity of the masseter muscle in young adults during chewing of two test foods. J Oral Rehabil, v.24, n.3, p.216-223, 1997.

58. KASHIWAGI, K.; TANAKA, M.; KAWAZOE, T.; FURUICHI, K.; TAKADA, H. Effect of amplitude normalization on surface EMG linear envelopes of masticatory muscles during gum chewing. J Osaka Dent Univ, v.29, n.1, p.19-28, 1995.

59. KAZAZOGLU E, HEATH MR, MULLER F. A simple test for determination of the preferred chewing side. J Oral Rehabilit, v.21, n.6, p.723-725, 1994.

60. KILIARIDIS, S.; ENGVALL, M.; TZAKIS, M.G. Ultrasound imaging of the masseter muscle in myotonic dystrophy patients. J Oral Rehabil, v.22, n.8, p.619-625, 1995.

61. KIM, S.K.; KIM, K.N.; CHANG, I.T.; HEO, S.J. A study of the effects of chewing patterns on occlusal wear. J Oral Rehabil, v.28, n.11, p.1048-1055, 2001.

62. KOSSIONI, A.E.; DONTAS, A.S. The stomatognathic system in the elderly. Useful information for the medical practitioner. Clin Interv Aging, v.2, n.4, p.591-597, 2007.

63. KURTH, L.E. Mandibular movements in mastication. J Am Dent Assoc, v.29, p.1769, 1942.

64. LOWE, A.A.; JOHNSTON, W.D. Tongue and jaw muscle activity in response to mandibular rotations in a sample of normal and anterior open-bite subjects. Am. J. Orthod, v.76, n.5, p.565-576, 1979.

65. LUND, J.P.; WIDMER, C.G. An evaluation of the use of surface electromyography in the diagnosis, documentation and treatment of dental patients. J Craniomandib Disord, v.3, n.3, p.125-137, 1989.

66. MAGALHÃES, I.B.; PEREIRA, L.J.; MARQUES, L.S.; GAMEIRO, G.H. The influence of malocclusion on masticatory performance. A systematic review. Angle Orthod, v.80, n.5, p.981-987, 2010.

67. MAHMOOD, W.A.; WATSON, C.J.; OGDEN, A.R.; HAWKINS, R.V. Use of image analysis in determining masticatory efficiency in patients presenting for immediate dentures. Int J Prosthodont, v.5, n.4, p.359-366, 1992.

68. MARCHESAN, I.Q. Motricidade oral: visão clínica do trabalho fonoaudiológico integrado com outras especialidades. São Paulo, Pancast, 1993.

69. MARCHIORI, S.C.; VITTI, M. Estudo eletromiográfico do músculo orbicular da boca. RGO, v.44, n.6, p.331-334, 1996.

70. MATHIASSEN SE, WINKEL J, HAGG GM. Normalization of surface EMG amplitude from the upper trapezius muscle in ergonomic studies: A review. J Electromyogr Kinesiol, v.5, n.4, p.197-226, 1995.

71. McNEILL C. Ciência e Prática da Oclusão. Trad. AJG Perrotti. São Paulo: Quintessence Edit, Ltda; 2000. 
72. MENDONCA, D.B.; PRADO, M.M.; MENDES, F.A.; BORGES, T. DE F.; MENDONÇA, G.; DO PRADO, C.J.; NEVES, F.D. Comparison of masticatory function between subjects with three types of dentition. Int J Prosthodont, v.22, n.4, p.399-404, 2009.

73. MICHELOTTI, A.; FARELLA, M.; VOLLARO, S.; MARTINA, R. Mandibular rest position and electrical activity of the masticatory muscles. J Prosthet Dent, v.78, n.1, p.48-53, 1997.

74. MINISTÉRIO DA SAÚDE: Projeto SB Brasil 2003: Condições de saúde bucal da população brasileira 2002-2003: Resultados Principais. Brasília: Ministério da Saúde; 2004.

75. MIOCHE, L.; BOURDIOL, P.; MARTIN, J.; NOËL, Y. Variations in human masseter and temporalis muscle activity related to food texture during free and side-imposed mastication. Arch Oral Biol, v.44, n.12, p.1005-1012, 1999.

76. MISHELLANY-DUTOUR, A.; RENAUD, J.; PEYRON, M.A.; RIMEK, F.; WODA, A. Is the goal of mastication reached in young dentates, aged dentates and aged denture wearers? Br J Nutr., v.99, n.1, p.121-8, 2008.

77. MIYAUCHI, S.; NAKAMINAMI, T.; NISHIO, K.; MARUYAMA, T. Chewing pattern in posterior crossbite. Classification of chewing pattern in the frontal plane. Nihon Hotetsu Shika Gakkai Zasshi, v.33, n.4, p.938-951, 1989.

78. MIZUMORI, T.; TSUBAKIMOTO, T.; IWASAKI, M.; NAKAMURA, T. Masticatory laterality-evaluation and influence of food texture. J Oral Rehabil, v.30, n.10, p.995999, 2003.

79. MOHL, M.D.; ZARB, G.A.; CARLSSON, G.E.; RUGH, J.D. Livro - texto de Oclusão. Chicago. Quintessence Inc. 1988.

80. MOLINA, O.F. Fisiopatologia craniomandibular. São Paulo: Pancast, 1989.

81. MONGINI, F. The Stomatognathic System. Chicago: Quintessence Publishing Co. Inc.; 1998.

82. MOWLANA, F.; HEATH, M.R.; VAN DER BILT, A.; VAN DER GLAS, H.W. Assessment of chewing efficiency: a comparison of particle size distribution determined using optical scanning and sieving of almonds. J Oral Rehabil, v.21, n.5, p.545-551, 1994.

83. MOWLANA, F.; HEATH, R. Assessment of masticatory efficiency: new methods appropriate for clinical research in dental practice. Eur J Prosthodont Restor Dent, v.1, n.3, p.121-125, 1993.

84. MOYERS R E. Ortodontia. Rio de Janeiro: Edit. Guanabara-Koogan, 4ª Edição; 1991.

85. MOYERS, R.E. Temporomandibular muscle contraction patterns in angle class II, division I malocclusions: an electromyographic analysis. Am J Orthod, v.35, n.11, p.837-857, 1949. 
86. OGAWA T, OGAWA M, KOYANO K. Different responses of masticatory movements after alteration of occlusal guidance related to individual movement pattern. $\mathbf{J}$ Oral Rehabil, v.28, n.9, p.830-841, 2001.

87. OKIYAMA, A.; IKEBE, K.; NOKUBI, T. Association between masticatory performance and maximal occlusal force in young men. J Oral Rehab, v.30, p.278-282, 2003.

88. OLIVEIRA DAL. Nova visão em ortodontia - ortopedia funcional dos maxilares. São Paulo: Livraria e Editora Santos, p.969-976, 2002.

89. ORCHARDSON, R.; CADDEN, S.W. Mastication and swallowing: 1. Functions, performance and mechanisms. Dent Update, v.36, n.6, p.327-330, 332-334, 337, 2009.

90. ORCHARDSON, R.; CADDEN, S.W. Mastication, in scientific basis of eating. Front Oral Biol, v.9, p.76-121, 1998.

91. PAESANI, D.A.; TALLENTS, R.H.; MURPHY, W.C.; HATALA, M.P.; PROSKIN, H.M. Evaluation of reproducibility of rest activity of the anterior temporal and masseter muscles in asymptomatic and symptomatic temporomandibular subjects. J Orofac. Pain, v.8, n.4, p.402-406, 1994.

92. PANCHERZ, H. Temporal and masseter muscle activity in children and adults with normal occlusion. Acta Odontol Scand, v.38, n.6, p.343-348, 1980.

93. PAPARGYRIOU, G.; KJELLBERG, H.; KILIARIDIS, S. Changes in masticatory mandibular movements in growing individuals: a six-year follow-up. Acta Odontol Scand, v.58, v.3, p.129-134, 2000.

94. PERA, P.; BASSI, F.; SCHIERANO, G.; APPENDINO, P.; PRETI, G. Implant anchored complete mandibular denture: evaluation of masticatory efficiency, oral function and degree of satisfaction. J Oral Rehabil, v.25, n.6, p.462-467, 1998.

95. PEYRON, M.A.; BLANC, O.; LUND, J.P.; WODA, A. Influence of age on adaptability of human mastication. J Neurophysiol, v.92, n.2, p.773-779, 2004.

96. PEYRON, M.A.; WODA, A. Adaptation of mastication in response to the characteristics of the individual or the food. Orthod Fr, v.77, n.4, p.417-430, 2006.

97. PIANCINO, M.G.; FARINA, D.; TALPONE F., CASTROFLORIO T., GASSINO G., MARGARINO V., BRACCO P. Surface EMG of jaw-elevator muscles and chewing pattern incomplete denture wearers. J Oral Rehabil, v.32, n.12, p.863-870, 2005.

98. PIGNATARO NETO, G.; BÉRZIN, F.; RONTANI, R.M.P. Identificação do lado de preferência mastigatória através do exame eletromiográfico comparado ao visual. $\mathbf{R}$ Dent Press Ortodon Ortopedi Fac, v.9, n.4, p.77-85, 2004.

99. PLANAS, P. La thérapeutique orthodontique la plus precoce. Avec les composites polymérisables avec l'ultra-violet. L'Orthodontie Française, v.48, p.117-185, 1977.

100. POIKELA A, KANTOMAA T, PIRTTINIEMI P. Craniofacial growth after a period of unilateral masticatory function in young rabbits. Eur J Oral Sci, v.105, n.4, p.331-337, 1997. 
101. RAMFJORD, S.P.; ASH, M.M. Oclusão. Trad. DF Vieira. Rio de Janeiro: Interamericana Ltda 3를 1984.

102. REGALO, S.C.; VITTI, M.; HALLAK, J.E.; SIÉSSERE, S.; PAGNANO, V.O.; SEMPRINI, M. Electromyographic analysis of upper and lower fascicles of the orbicularis oris muscle in deaf individuals, in mandibular rest position, compared to hearers. Electromyog Clin Neurophysiol, v.46, n.4, p.211-215, 2006a.

103. REGALO, S.C.; VITTI, M.; SEMPRINI, M.; ROSA, L.B.; MARTINEZ, F.H.; SANTOS, C.M.; HALLAK, J.E. Electromyographic analysis of the masseter and temporal muscles in oralized deaf individuals. Electromyog Clin Neurophysiol., v.46, n.4, p.217-222, 2006b.

104. REGALO, S.C.H.; VITTI, M.; HALLAK, J.E.C.; SEMPRINI, M.; MATTOS, M.G.; TOSELLO, D.O.; CONSTANCIO, R.F.; PEGORARO, M.E.; LOPES, R.A. EMG analysis of the upper and lower fascicles of the orbicularis oris muscle in deaf individuals. Electromyogr Clin Neurophysiol, v.43, n.6, p.367-72, 2003.

105. REGALO, S.C.H.; VITTI, M.; OLIVEIRA, A.S.; SANTOS, C.M.; SIÉSSERE, S. Interfaces da Medicina, Odontologia e Fonoaudiologia no Complexo CérvicoCraniofacial - vol. 1. Barueri:Pró-Fono. 2008.

106. RILO, B.; SANTANA, U.; MORA, M.J.; CADARSO, C.M. Myoelectrical activity of clinical rest position and jaw muscle activity in young adults. J Oral Rehabil, v.24, n.10, p.735-740, 1997.

107. ROSA, L.B. Efeito das reabilitações bucais na atuação da musculatura do sistema estomatognático - avaliação eletromiográfica, ultrassonográfica, força de mordida e eficiência mastigatória. [Tese de doutorado], Ribeirão Preto: Faculdade de Odontologia de Ribeirão Preto da Universidade de São Paulo; 2010.

108. SAITOH, I.; HAYASAKI, H.; IWASE, Y.; NAKATA, M. Improvement in jaw motion following treatment of unilateral crossbite in a child with primary dentition: a case report. Cranio, v.20, n.2, p.129-134, 2002.

109. SANTOS, C.M. Efeitos do uso de overdenture sobre implantes e de próteses totais na atividade eletromiográfica da musculatura da mastigação. [Dissertação de mestrado], Ribeirão Preto: Faculdade de Odontologia de Ribeirão Preto da Universidade de São Paulo; 2005.

110. SANTOS, C.M.; VITTI, M.; MATSUMOTO, W.; BERRO, R.J.; SEMPRINI, M.; HALLAK, J.E.C.; et al. Using overdenture on implants and complete dentures: effects on postural maintenance of masticatory musculature. Braz J Oral Sci, v.7, p.15501554, 2008.

111. SCHIMIDT, R.F. Neurofisiologia, São Paulo: Editora Pedagógica e Universitária; 1979.

112. SENIAM 7. The state of the Art on Signal Processing Methods for Surface Electromyography, deliverable of the SENIAM project. eds. Hermens, H.J.; Merletti, B.F. Roessing Res. and Development b. v., 1999, ISBN: 90-75452-17-9.

113. SGOBBI DE FARIA, C.R.S.; BÉRZIN, F. Electromyographic study of the temporal, masseter and suprahyoid muscle in mandibular rest position. J Oral Rehabil, v.25, n.10, p.776-780, 1998. 
114. SIÉSSERE, S.; SOUSA, L.G.; LIMA, N. DE A.; SEMPRINI, M.; VASCONCELOS, P.B.; WATANABE, P.C.; RANCAN, S.V.; REGALO, S.C. Electromyographic activity of masticatory muscles in women with osteoporosis. Braz Dent J, v.20, n.3, p.237342, 2009.

115. SIMÕES, W.A. Mastication. J Orthod Soc., v.38, n.3, p.322-332, 1979.

116. SIMÕES, W.A. Visão do crescimento mandibular e maxilar. J Bras Ortodon Ortop Facial, v.3, n.15, p.9-18. 1998.

117. SLAGTER, A.P.; BOSMAN, F.; VAN DER GLAS, H.W.; VAN DER BILT, A. Human jaw-elevator muscle activity and food comminution in the dentate and edentulous state. Arch Oral Biol, v.38, n.3, p.195-205, 1993.

118. SODEBERG, G.L.; COOK, T.M. Electromyography in biomechanics. Phys. Ther, v. 64, n. 12, p. 1813-1820, 1984.

119. TALLGREN, A.; LANG, B.R.; HOLDEN, S.; MILLER, R.L. Longitudinal electromyographic study of swallowing patterns in complete denture wearers. Int $\mathbf{J}$ Prosthodont, v.8, n.5, p.467-478. 1995.

120. THEXTON, A.J. Até que ponto a mastigação é programada e independente de Retroalimentação Periférica? In: Matthews B. Mastigação. Rio de Janeiro: Guanabara Koogan S.A. 1982.

121. TOMIYAMA, N.; ICHIDA, T.; YAMAGUCHI, K. Electromyographic activity of lower lip muscles when chewing with the lips in contact and apart. Angle Orthod, v.74, n.1, p.31-36, 2004.

122. TOSELLO, D.O.; VITTI, M.; BÉRZIN, F. EMG activity of the orbicularis oris and mentalis muscles in children with malocclusion, incompetent lips and atypical swallowing--part I. J Oral Rehabil., v.25, n.11, p.838-846, 1998.

123. TSUGA, K.; CARLSON, G.E.; OSTERBERG, T.; KARLSSON, S. Self-assessed masticatory ability in relation to maximal bite force and dental state in 80-year-old subjects. J Oral Rehabil, v.25, n.2, p.117-124, 1998.

124. TZAKIS, M.G.; KARLSSON, S.; CARLSSON, G.E. Effects of intense chewing on some parameters of masticatory function. J Prosthet Dent, v.67, n.3, p.405-409, 1992.

125. TZAKIS, M.G.; KILIARIDIS, S.; CARLSSON, G.E. Effect of chewing training on masticatory efficiency. Acta Odontol Scand, v.47, n.6, p.355-360, 1989.

126. VAN DER BILT, A. Human oral function: a review. Braz J Oral Sci, v.1, n.1, p.7-18. 2002.

127. VAN DER BILT, A.; OLTHOFF, L.W.; BOSMAN, F.; OOSTERHAVEN, S.P. The effect of missing postcanine teeth on chewing performance in man. Arch Oral Biol, v.38, n.5, p.423-429, 1993.

128. VAN DER LAAN, T. Função mastigatória em índios lanomâmi [Dissertação de mestrado]. Piracicaba: Faculdade de Odontologia de Piracicaba da Universidade de Campinas; 1998. 
129. VAN DER LINDEN, F.P.M. Crescimento e ortopedia facial. Rio de Janeiro: Quintessence; 1990.

130. VIANNA-LARA, M.S.; CARIA, P.H.; TOSELLO DDE, O.; LARA, F.; AMORIM, M.M. Electromyographic activity of masseter and temporal muscles with different facial types. Angle Orthod, v.79, n.3, p.515-520, 2009.

131. VITTI, M.; BASMAJIAN, J.V. Muscles of mastication in small children: an electromyographic analysis. Am. J. Orthod, v.68, n.4, p.412-419, 1975.

132. WICKWIRE, N.A.; GIBBS, C.H.; JACOBSON, A.P.; LUNDEEN, H.C. Chewing patterns in normal children. Angle Orthod, v.51, n.1, p.48-60 1981.

133. WILDING, R.J. The association between chewing efficiency and occlusal contact area in man. Arch Oral Biol, v.38, n.7, p.589-596, 1993.

134. WILDING, R.J.; ADAMS, L.P.; LEWIN, A. Absence of association between a preferred chewing side and its area of functional occlusal contact in the human dentition. Arch Oral Biol, v.37, n.5, p.423-8, 1992.

135. WINTER, D.A. Pathologic Gait Diagnosis with Computer-Averaged Electromyographic Profiles. Arch Phys Med Rehabil, v.65, n.7, p.393-398, 1984.

136. YAMASHITA, S.; HATCH, J.P.; RUGH, J.D. Does chewing performance depend upon a specific masticatory pattern? J Oral Rehabil, v.26, n.7, p.547-53, 1999.

137. YOUSSEF, R.E.; THROCKMORTON, G.S.; ELLIS, E. 3rd.; SINN, D.P. Comparison of habitual masticatory patterns in men and women using a custom computer program. J Prosthet Dent, v.78, n.2, p.179-86, 1997.

138. ZHAO, L.; MONAHAN, R. Functional Assessment of the Stomatognathic System. Clin Plast Surg, v.34, n.3, p.1-9, 2007.

139. ZUCCOLOTTO, M.C.; VITTI, M.; NOBILO, K.A.; REGALO, S.C.; SIESSERE, S.; BATAGLION, C. Electromyographic evaluation of masseter and anterior temporalis muscles in rest position of edentulous patients with temporomandibular disorders, before and after using complete dentures with sliding plates. Gerodontology, v.24, n.2, p.105-110, 2007. 







\section{Anexo I - Termo de Consentimento Livre e Esclarecido}

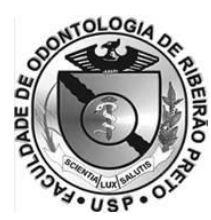

\section{Universidade de São Paulo \\ Faculdade de Odontologia de Ribeirão Preto \\ Departamento de Odontologia Restauradora - opção: \\ Dentística}

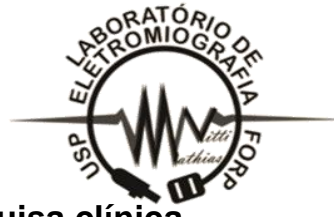

Termo de Consentimento Livre e Esclarecido para pesquisa clínica

$\mathrm{Eu}$, RG:

fui convidado para participar de um programa de pesquisa em Eletromiografia do Departamento de Morfologia da Faculdade de Odontologia de Ribeirão Preto, Universidade de São Paulo, a qual tem por objetivo um melhor entendimento da função dos músculos da face.

A pesquisa tem por finalidade verificar o funcionamento da região da face por meio do emprego da Eletromiografia (que é um processo que capta sinais elétricos dos músculos) usando para isso eletrodos de superfície sobre a pele dos locais onde estão localizados os músculos. Não existem riscos previsíveis e os benefícios esperados resumem-se em saber a função dos músculos. Entende-se também, que não há métodos alternativos para a realização desta pesquisa, e que não haverá outra forma de acompanhamento, assistência e/ou tratamento clínico após a realização dos registros eletromiográficos. Antes de iniciar os testes, você será instruído sobre os procedimentos a serem seguidos: os voluntários permanecerão sentados confortavelmente em uma cadeira para a execução de alguns movimentos, por no máximo 20 segundos para cada movimento. As regiões dos músculos serão limpas com álcool para a limpeza dos resíduos gordurosos presentes na pele e fitas adesivas (eletrodos de superfície) serão colocados na área dos músculos em estudo.

Afirmo que a minha participação é voluntária sendo que os procedimentos a serem realizados foram apresentados e claramente explicados a mim pelos pesquisadores responsáveis, ficando explícito para mim que nenhum dos procedimentos a serem realizados compromete a minha integridade física ou emocional. Os pesquisadores Simone Cecilio Hallak Regalo e Cristiane Savaris se comprometem a prestar assistência integral no decorrer da pesquisa. Se necessário, devo entrar em contato pelos telefones: 3602-4015; 8189-2868.

Entendo que posso fazer qualquer pergunta sobre os procedimentos e que eu sou livre para rescindir meu consentimento e interromper a minha participação nesta pesquisa a qualquer momento, sem nenhum prejuízo de minha parte. Tenho também, por parte dos pesquisadores, a garantia do sigilo que assegura a minha privacidade.

Entendo também que este estudo está sendo realizado em benefício das ciências médica e odontológica e concordo com a divulgação dos dados obtidos através de publicação científica.

Caso ocorra algum dano à minha saúde, em razão da participação na pesquisa, os pesquisadores serão responsáveis por quaisquer despesas.

Ribeirão Preto de de

Assinatura do Voluntário 


\section{Anexo II - Comitê de Ética em Pesquisa}

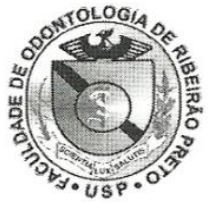

Of. CEP / 287 / FORP

\section{UNIVERSIDADE DE SÃO PAULO \\ Faculdade de Odontologia de Ribeirão Preto Comitê de Ética em Pesquisa}

Senhora Pesquisadora,

A pedido da Profa. Dra. Cláudia Helena Lovato da Silva, Coordenadora do Comitê de Ética em Pesquisa, desta Faculdade, informamos que o referido Comitê em sua $110^{\text {a }}$ Sessão, realizada em 24 de junho de 2010, aprovou a solicitação de alteração do pesquisador responsável e prorrogação de prazo por 24 meses para desenvolvimento do Projeto de Pesquisa: "Efeito das reabilitações orais na atuação da musculatura do sistema estomatognático - Avaliação eletromiográfica, ultrassonográfica, força de mordida e eficiência mastigatória".

$\mathrm{Na}$ oportunidade, lembramos da necessidade de serem entregues, na Secretaria do Comitê, com os respectivos formulários preenchidos pelo pesquisador responsável, o Relatório Parcial em 24/06/2011 e o Relatótio Final em 24/06/2012.

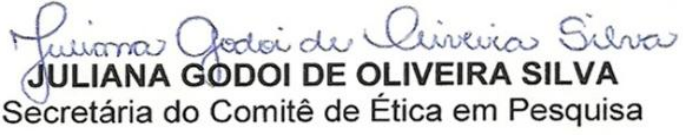

IIma. Sra.

Profa. Dra. SIMONE CECÍLIO HALLAK REGALO

Departamento de Morfologia, Estomatologia e Fisiologia desta Faculdade 


\title{
Anexo III - Autorização de uso da imagem
}



\author{
Universidade de São Paulo \\ Faculdade de Odontologia de Ribeirão Preto
}

Ribeirão Preto, 19 de dezembro de 2010

\section{AUTORIZAÇÃO}

Eu, Mariangela Salles Pereira Nassar RG; 16236151,8, CPF; 049757428/45 autorizo a divulgação das minhas imagens na Tese de Doutorado intitulada: EFEITO DAS REABILITAÇÕES BUCAIS NA EFICIÊNCIA DE CICLOS MASTIGATÓRIOS ANÁLISE ELETROMIOGRÁFICA POR MEIO DA INTEGRAL DA ENVOLTÓRIA

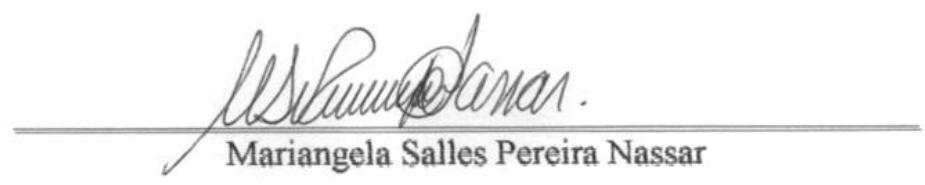

